\title{
FUZZY DECISION MAKING METHOD BASED ON COCOSO WITH CRITIC FOR FINANCIAL RISK EVALUATION
}

\author{
Xindong PENG ${ }^{*}$, Haihui HUANG ${ }^{\circledR}$ \\ School of Information Science and Engineering, Shaoguan University, Shaoguan, China
}

Received 04 June 2019; accepted 30 October 2019

\begin{abstract}
The financial risk evaluation is critically vital for enterprises to identify the potential financial risks, provide decision basis for financial risk management, and prevent and reduce risk losses. In the case of considering financial risk assessment, the basic problems that arise are related to strong fuzziness, ambiguity and inaccuracy. q-rung orthopair fuzzy set (q-ROFS), portrayed by the degrees of membership and non-membership, is a more resultful tool to seize fuzziness. In this article, the novel q-rung orthopair fuzzy score function is given for dealing the comparison problem. Later, the $\ominus$ and $\oslash$ operations are explored and their interesting properties are discussed. Then, the objective weights are calculated by CRITIC (Criteria Importance Through Inter-criteria Correlation). Moreover, we present combined weights that reflects both subjective preference and objective preference. In addition, the q-rung orthopair fuzzy MCDM (multi-criteria decision making) algorithm based on CoCoSo (Combined Compromise Solution) is presented. Finally, the feasibility of algorithm is stated by a financial risk evaluation example with corresponding sensitivity analysis. The salient features of the proposed algorithm are that they have no counter-intuitive case and have a stronger capacity in differentiating the best alternative.
\end{abstract}

Keywords: financial risk evaluation, q-rung orthopair fuzzy set, CoCoSo, combined weights, score function, CRITIC.

JEL Classification: C43, C61, D81.

\section{Introduction}

Financial risk refers to the possibility that the ultimate financial results achieved by a company in a specified time and within a specified range out of line with the desired business goal due to multiple uncontrollable and unpredictable factors in diverse financial activities, thus resulting in economic losses or greater profits for the enterprise. The financial activities of a company are throughout the all course of operation and production. Raising capital, making long- and short-term investments, and distributing profits may all bring risks. Financial risk is a practical issue that companies must confront in the financial management process.

\footnotetext{
*Corresponding author. E-mail: 952518336@qq.com
}

\section{(C) 2020 The Author(s). Published by VGTU Press}

This is an Open Access article distributed under the terms of the Creative Commons Attribution License (http://creativecommons. org/licenses/by/4.0/), which permits unrestricted use, distribution, and reproduction in any medium, provided the original author and source are credited. 
Financial risks are objective that enterprise manager only takes efficient ways to lower risks and not completely eliminate risks. In today's world, it is not uncommon for companies to fail or go bankrupt due to financial risks, even very large enterprises such as Enron, one of the Fortune Global 500 companies in 2002. Therefore, ignoring financial risks will bring us serious consequences.

Financial risk indicators are financial analysis methods based on broad-based financial activities, from the perspective of dynamics and long-term, setting sensitive financial indicators and observing their changes, and monitoring and forecasting financial risks that the company may or will face. It is the unification of financial indicators and financial early warning models. The former is the embodiment of the financial evaluation system of the enterprise to report the financial risk. The latter is based on the combination of multiple financial indicators, select multiple enterprise samples, establish a multi-variable mathematical model, and conduct a more comprehensive and in-depth analysis of enterprise financial risk, which has the value of macro analysis. The aim of analyzing financial risk indicators is to recognize underlying financial risks of companies by setting financial risk warning and warning index on the basis of detecting the financial status and financial results of enterprises, so as to provide decision basis for financial risk management, and prevent and reduce risk losses. The design principles of financial risk indicators are mainly shown in Figure 1.

In the process of financial risk evaluation (FRE), enterprises are assessed by professional with diverse financial risk indicators can be treated as MCDM (multi-criteria decision making) issue. To evaluate the financial risk of enterprises' performance, diverse effective methods have already been developed. Duan (2019) employed the deep neural networks for assessing and predicting the assessment of financial system. Gerrard et al. (2019) developed a simple communication tool for enabling financial risk of the optimal investment profile. Goda and Tesfamariam (2019) presented the financial risk assessment of buildings in Victoria and Montreal. Nevertheless, these scholars only consider the entire evaluation of financial risk, but fail to consider individual evaluations (assessments of financial risk over diverse indicators). Also, for assessing the financial risk of enterprise, there exists much indeterminate and inconclusive information. Under such environment, the chief financial officer (CFO)

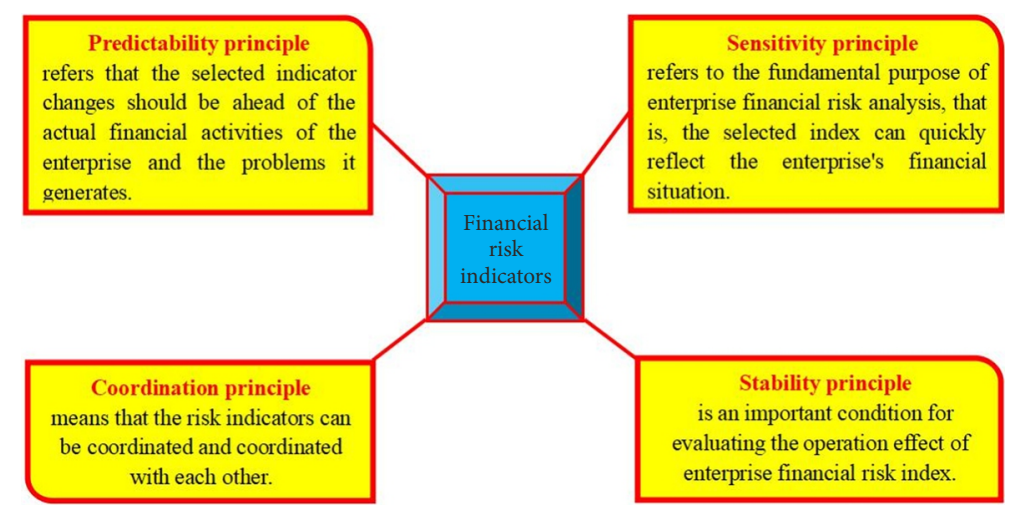

Figure 1. The four principles of financial risk indicators 
make decisions with a strong capability in differentiating the best alternative. In addition, the uncertainty of assessing the financial risk of enterprise decides that the CFO fails to provide the pinpoint preference information if they face with various options. While some existing theories such as intuitionistic fuzzy set (IFS) (Atanassov, 1986), and Pythagorean fuzzy set (PFS) (Yager, 2014) have been employed in imitating fuzziness. The above theories possess their intrinsic shortcomings and restrictions (Peng \& Selvachandran, 2019).

Lately, q-rung orthopair fuzzy set (q-ROFS), initially developed by Yager (2017), has been served as a resultful means to depict fuzziness in MCDM issues. The q-ROFS is portrayed by the degrees of membership and non-membership, whose sum of the corresponding $q$ th power is less than or equal to 1 . It is easy to understand that as the rung $q$ increases, the corresponding acceptable orthopairs space increases, which more orthopairs meet the limited condition. That is to say, the q-ROFS is generic form because IFS and PFS are both its particular form. Consequently, q-ROFS is more appropriate and befitting for the indeterminate environment. In view of such advantage of the q-ROFS, it is fast becoming a hot study topic, containing aggregation operators, information measure, decision making methods and calculus.

- Aggregation operators: In 2018, Liu and Wang (2018a) developed two q-rung orthopair fuzzy aggregation operators (q-ROFAO) for aggregating the assessment values of potential companies. Xing et al. (2019) brought point operators into q-ROFAO (Liu \& Wang, 2018a), which can make them more flexible in the decision process. Peng et al. (2018) presented novel aggregation operators (AOs) based on novel exponential operational law under q-rung orthopair fuzzy (q-ROF) environment. For considering interrelationships between criteria, the Bonferroni Mean (BM) operator (Bonferroni, 1950 ) is taken into consideration by combining the q-ROFS (Liu \& Liu, 2018; Liu \& Wang, 2018b; Yang \& Pang, 2019). Moreover, the Maclaurin symmetric mean (MSM) operator (Laurin, 1729) and Heronian mean (HM) operator (Beliakov et al., 2007) are also resultful approach to seize the correlation among the multi-input arguments, which have been applied them in combining the advantage of q-ROFS (Wei et al., 2019; Wang et al., 2018; Liu et al., 2018a). Further, Wang et al. (2019) explored a more general form of Muirhead means (MM) operator (Muirhead, 1902) into q-ROF environment that the AOs (Liu \& Wang, 2018a, 2018b; Liu \& Liu, 2018) can be their special cases.

- Information measures: Liu et al. (2019) developed cosine similarity measures and distance measures based q-ROFS. Du $(2018,2019)$ proposed q-rung orthopair fuzzy distance measures, correlation and correlation coefficient with Minkowski-type and proved their interesting properties. Peng and Liu (2019) explored the scientific transition of information measure (distance measure, entropy, similarity measure, inclusion measure) for q-ROFS, and proposed some new formulae for q-rung orthopair fuzzy information measure. Moreover, they successfully applied q-rung orthopair fuzzy similarity measure to medical diagnosis, clustering analysis and pattern recognition.

- Decision making methods: In addition to the AOs (Liu \& Wang, 2018a, 2018b; Xing et al., 2019) and information measures (Liu et al., 2019; Du, 2018) mentioned above 
can be employed in integrating the entire preference information. Liu et al. (2018b) presented a MCDM method for disposing of heterogeneous relationship among criteria with uncharted weight information under q-ROF environment. Wang and $\mathrm{Li}$ (2018) developed a q-rung orthopair fuzzy TODIM (TOmada de Decisao Interativa e Multicritevio) method based on prospect theory for achieving the optimal green supplier. Peng and Dai (2019) explored the q-rung orthopair fuzzy decision making method based on CODAS (combinative distance-based assessment) and multiparametric similarity measure, and successfully applied them in assessing the classroom teaching quality.

- Calculus: Ye et al. (2019) defined the notion of q-rung orthopair single variable fuzzy function (q-ROSVFF) for depicting the fuzzy continuous information. Gao et al. (2019) explored derivatives, continuities and differentials of q-ROSVFF. Shu et al. (2019) presented q-rung orthopair fuzzy definite integrals (q-ROFDIs), constructed the q-ROFDIs, gave their specific values, and discussed their integrability criteria through two perspectives.

Figure 2 illustrates the top 5 application fields of q-ROFS. In Figure 2, the fields of colored rectangles show the numbers of applications with q-ROF environment. As can be seen, the most popular application fields are computer science, science technology other topics, and mathematics.

When we handle some q-rung orthopair fuzzy MCDM problems, there are four deficiencies, which form our incentives.

1. The existing AOs (Liu \& Wang, 2018a, 2018b; Xing et al., 2019) employing in solving MCDM issues have counter-intuitive cases (Peng et al., 2018) and low discernibility degree in differentiating the best alternative. It may be unmerited or impracticable for decision makers (DMs) to select optimal alternative. The CoCoSo (Combined Compromise Solution) method, firstly developed by Yazdani et al. (2018), is an adaptive algorithm to dispose the information in a logical and viable way. Consequently, the 1st incentive is to handle the MCDM problems by presenting novel algorithm without two defects above.

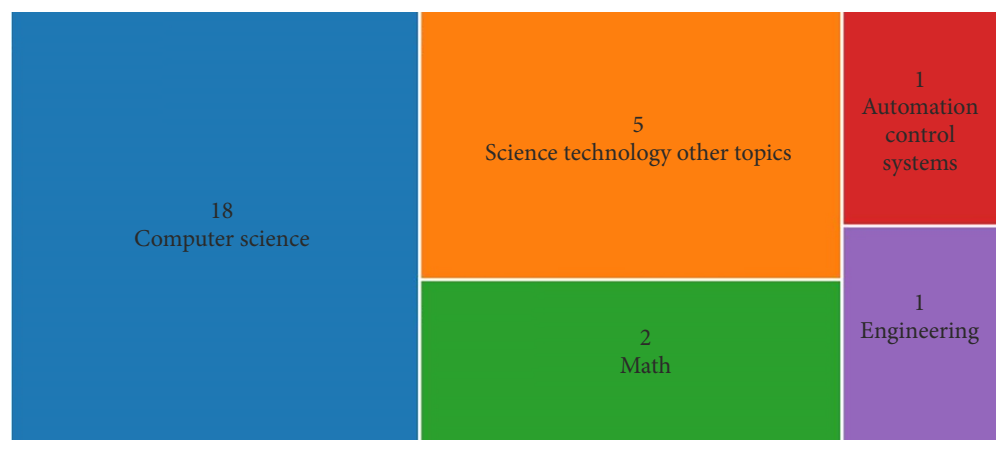

Figure 2. Top 5 diverse application fields of q-ROFS 
2. Some existing score functions (Liu \& Wang, 2018a; Peng et al., 2018; Peng \& Dai, 2019) cannot precisely rank the q-ROFNs in some special cases. Moreover, we can see that the score functions (Liu \& Wang, 2018a; Peng \& Dai, 2019) cannot think the impact of hesitation case, which indicates that the corresponding information is incomplete. Consequently, the 2 nd incentive is to bring a novel score function that to consider the hesitation case.

3. The existing q-ROF weighting determining methods only think objective weight (Liu et al., 2018b) or subjective weight (Liu \& Wang, 2018a, 2018b; Xing et al., 2019). The subjective weight is offered by DMs while they neglect the weight information transmitted by the evaluation matrix. However, the objective weight can be achieved from the evaluation matrix by some effective methods while they cannot consider the DMs' preference information. How to integrate them is a hot topic (Wang \& $\mathrm{Li}, 2018$ ). Consequently, the 3rd incentive is to bring the combined weight model that to consider both subjective preference and objective preference.

4. The existing operations (Yager, 2017) on q-ROFS are not affluent and their relations are not well discussed. Moreover, some operations (Peng et al., 2018) such as $\ominus, \oslash$ are so complex and many limit conditions, which is hard to deal with decision data. Consequently, the 4 th incentive is to present more $q$-ROF operations and also explore their wonderful relations.

Based on the above four incentives and the character of financial risk evaluation, this article presents new q-ROF MCDM method. The innovations of the proposed method is listed in the following.

1. The novel q-ROF financial risk decision making method based on CoCoSo is developed, which can achieve the best alternative out of counter-intuitive case and have a strong capacity in differentiating the most desired alternative.

2. The novel q-ROF score function is developed, which consider the hesitation case that lowering the evaluation information losses. In addition, some desired theorems are explored.

3. The combined weight method is based on CRITIC (Criteria Importance Through Inter-criteria Correlation) and the linear weighted comprehensive method that to simultaneously consider subjective information and objective information.

4. Novel revised operations ( $\ominus$ and $\oslash$ ) and their affluent relations are given and proved, respectively.

To process our discussion, the remainder of this article is listed as follows: Section 1 reviews the basic notions of q-ROFS. In Section 2, the novel q-ROF score function is presented and its affluent relations are proved. In Section 3, the novel q-ROF operations are presented and explored. In Section 4, we present a new q-ROF financial risk decision making method based on CoCoSo with CRITIC, and the sensitive analysis is shown. In Section 5 gives numerical examples to state the effectiveness of developed algorithm. In last section, some conclusions are derived. 


\section{Preliminaries}

This section chiefly reviews the notions of q-rung orthopair fuzzy set (q-ROFS).

Definition 1 (Yager, 2017). Let $X$ be domain of discourse. The q-ROFS $A$ in $X$ is expressed as

$$
A=\left\{\left\langle x, \mu_{A}(x), v_{A}(x)\right\rangle \mid x \in X\right\},
$$

where $\mu_{A}: X \rightarrow[0,1]$ and $v_{A}: X \rightarrow[0,1]$ denote the degrees of membership and nonmembership of the element $x \in X$ to the set $A$, respectively. Its limited condition must meet $0 \leq\left(\mu_{A}(x)\right)^{q}+\left(v_{A}(x)\right)^{q} \leq 1(q \geq 1)$. The degree of indeterminacy $\pi_{A}(x)=\left(1-\left(\mu_{A}(x)\right)^{q}-\right.$ $\left.\left(v_{A}(x)\right)^{q}\right)^{1 / q}$. For simple, Yager (2017) defined $a=(\mu, v)$ as q-rung orthopair fuzzy number (q-ROFN).

Definition 2 (Liu \& Wang, 2018a). For two q-ROFNs $a=\left(\mu_{1}, v_{1}\right)$ and $b=\left(\mu_{2}, v_{2}\right)$, then the comparison rule of score function can be expressed in the following.

(1) If $S(\mathrm{a})>S(\mathrm{~b})$, then $a>b$;

(2) If $S(\mathrm{a})<S(\mathrm{~b})$, then $a<b$;

(3) If $S(\mathrm{a})=S(\mathrm{~b})$, then

If $\pi_{1}>\pi_{2}$, then $a<b$;

If $\pi_{1}=\pi_{2}$, then $a=b$.

Definition 3 (Liu \& Wang, 2018a; Peng \& Dai, 2019). Let $a=\left(\mu_{1}, v_{1}\right)$ and $b=\left(\mu_{2}, v_{2}\right)$ be two q-ROFNs, then the operations can be denoted.

(1) $a \bigcup b=\left(\max \left\{\mu_{1}, \mu_{2}\right\}, \min \left\{v_{1}, v_{2}\right\}\right)$;

(2) $a \bigcap b=\left(\min \left\{\mu_{1}, \mu_{2}\right\}, \max \left\{v_{1}, v_{2}\right\}\right)$;

(3) $a^{c}=\left(v_{1}, \mu_{1}\right)$;

(4) $a \oplus b=\left(\sqrt[q]{\mu_{1}^{q}+\mu_{2}^{q}-\mu_{1}^{q} \mu_{2}^{q}}, v_{1} v_{2}\right)$;

(5) $a \otimes b=\left(\mu_{1} \mu_{2}, \sqrt[q]{v_{1}^{q}+v_{2}^{q}-v_{1}^{q} v_{2}^{q}}\right)$;

(6) $\lambda a=\left(\sqrt[q]{1-\left(1-\mu_{1}^{q}\right)^{\lambda}}, v_{1}^{\lambda}\right), \lambda>0$;

(7) $a^{\lambda}=\left(\mu_{1}^{\lambda}, \sqrt[q]{1-\left(1-v_{1}^{q}\right)^{\lambda}}\right), \lambda>0$;

(8) $a \ominus_{\mathrm{O}} b=\left(\sqrt[q]{\frac{\mu_{1}^{q}-\mu_{2}^{q}}{1-\mu_{2}^{q}}}, \frac{v_{1}}{v_{2}}\right)$, if $\mu_{1} \geq \mu_{2}, v_{1} \leq \min \left\{v_{2}, \frac{v_{2} \pi_{1}}{\pi_{2}}\right\}$;

(9) $a \oslash_{\mathrm{O}} b=\left(\frac{\mu_{1}}{\mu_{2}}, \sqrt[q]{\frac{v_{1}^{q}-v_{2}^{q}}{1-v_{2}^{q}}}\right)$, if $v_{1} \geq v_{2}, \mu_{1} \leq \min \left\{\mu_{2}, \frac{\mu_{2} \pi_{1}}{\pi_{2}}\right\}$. 


\section{A novel q-rung orthopair fuzzy score function}

This section reviews some existing score functions (Liu \& Wang, 2018a; Peng et al., 2018; Peng \& Dai, 2019), discusses their drawbacks, and presents a novel score function by taking hesitant attitudinal into consideration.

\subsection{Some existing q-rung orthopair fuzzy score functions}

Assume that a q-ROFN is expressed by $a=(\mu, v)$, where $\mu, v$ denote for the pro and con, respectively. Liu and Wang (2018a) presented the following score function.

$$
S_{\text {liu }}(a)=\mu^{q}-v^{q},
$$

where $S_{\text {liu }}(a) \in[-1,1]$. It can be easily seen that the bigger the $S_{\text {liu }}(a)$ is, the larger the $\mathrm{q}-\mathrm{ROFN}$ is.

Remark 1. When $q=1$, it degrades into $S_{c t}(a)=\mu-v$ (Chen \& Tan, 1994); When $q=2$, it degrades into $S_{z x}(a)=\mu^{2}-v^{2}$ (Zhang \& Xu, 2014).

Example 1. Given that $a=(0.4,0.4)$ and $b=(0.5,0.5)$. If we employ score function $S_{\text {liu }}$ (Liu \& Wang, 2018a) to choose the largest q-ROFN, we can have $S_{l i u}(a)=S_{l i u}(b)=0$. Therefore, we can't differentiate the discrepancy, which reveals that such score function fails to rank in such condition.

Notice the drawbacks (Liu \& Wang, 2018a), they presented the definition of accuracy function:

where $H_{\text {liu }}(a) \in[0,1]$.

$$
H_{\text {liu }}(a)=\mu^{q}+v^{q}
$$

Remark 2. If $q=1$, it degrades into $H_{h c}(a)=\mu+v$ (Hong \& Choi, 2000); If $q=2$, it degrades into $H_{\text {peng }}(a)=\mu^{q}+v^{q}$ (Peng \& Yang, 2015).

The score function $S_{l i u}$ can precisely rank the common alternatives. Nevertheless, Peng et al. (2018) discovered that score function $S_{l i u}$ and accuracy $H_{l i u}$ fail to take the impact of hesitance into consideration, which means that the potential information will not be integrated. So they presented a new score function in the following.

$$
S_{p x}(a)=\mu^{q}-v^{q}+\left(\frac{e^{\mu^{q}-v^{q}}}{e^{\mu^{q}-v^{q}}+1}-\frac{1}{2}\right) \pi^{q} .
$$

It also can be found that the score function (Peng et al., 2018) also confronted the same case when $\mu=v$. In other words, $S_{p x}$ will degrade into $S_{\text {liu }}$.

Moreover, Peng and Dai (2019) proposed another score function $S_{\lambda}^{p}(a)$, which also take the influence of hesitation into consideration.

$$
S_{\lambda}^{p}(a)=\frac{\mu^{q}-2 v^{q}-1}{3}+\frac{\lambda}{3}\left(\mu^{q}+v^{q}+2\right), \lambda \in[0,1] .
$$

\subsection{The novel score function}

Definition 4. For any q-ROFN $a=(\mu, v)$, the novel score function can be denoted as

$$
S_{p x d}(a)=\mu^{q}-v^{q}-\ln \left(1+\pi^{q}\right), S_{p x d}(a) \in[-1,1] .
$$


Theorem 1. For any q-ROFN $a=(\mu, v), S_{p x d}(a)$ monotonically increases and monotonically decreases when the increase of $\mu$ and $v$, respectively.

Proof. By means of the Eq. (6), we have corresponding first partial derivative of $S_{p x d}(a)$ with $\mu$,

$$
\frac{\partial S_{p x d}(a)}{\partial \mu}=q \mu^{q-1}\left(1+\frac{1}{2-\mu^{q}-v^{q}}\right) \geq 0 .
$$

Similarly, we can obtain the corresponding first partial derivative of $S_{p x d}(a)$ with $v$,

$$
\frac{\partial S_{p x d}(a)}{\partial v}=q v^{q-1}\left(\frac{1}{2-\mu^{q}-v^{q}}-1\right) \leq 0 .
$$

Hence, the theorem is proved.

Theorem 2. For any q-ROFN $a=(\mu, v)$, the new score function $S_{p x d}(a)$ abides by the following relations.

(1) $-1 \leq S_{p x d}(a) \leq 1$

(2) $S_{p x d}(a)=1$ iff $a=(1,0)$;

(3) $S_{p x d}(a)=-1$ iff $a=(0,1)$.

Proof. By means of Theorem 1, we can see that if we just consider $\mu$ or $v, S_{p x d}(a)$ can possess the min-value or max-value when $a=(0,1)$ or $a=(1,0)$. In other words, $S_{p x d}(a)_{\min }=$ -1 and $S_{p x d}(a)_{\max }=1$. Hence, $-1 \leq S_{p x d}(a) \leq 1$.

Theorem 3. Let $a=\left(\mu_{1}, v_{1}\right)$ and $b=\left(\mu_{2}, v_{2}\right)$ be two q-ROFNs. If $\mu_{1}>\mu_{2}$ and $v_{1}<v_{2}$, then $S_{p x d}(a)>S_{p x d}(b)$.

Proof. According to Theorem 1, we will find that $S_{p x d}(a)$ monotonically increases and monotonically decreases when the increase of $\mu$ and $v$, respectively.

$$
\text { Consequently, if } \mu_{1}>\mu_{2} \text { and } v_{1}<v_{2} \text {, then } S_{p x d}(a)>S_{p x d}(b) \text {. }
$$

To test the effectiveness of the introduced score function $S_{p x d}$, Table 1 displays a comparison among the ranking results achieved by the developed score function $S_{p x d}$ and the conditions of the existing score functions induced by $S_{\text {liu }}, S_{\lambda}^{p}(\lambda=0)$ and $S_{p x}$ (The red background color presents illogical results and the blue background color denotes counterintuitive results).

According to Table 1, it can be easily found that the introduced score function $S_{p x d}$ can availably handle some deficiencies of $S_{p x}$ (Peng, Dai, \& Garg, 2018), $S_{\lambda}^{p}$ (Peng \& Dai, 2019) and $S_{\text {liu }}$ (Liu \& Wang, 2018a) in all Cases. That is to say, the introduced score function can identify the difference of two diverse q-ROFNs while some existing score functions fail to obtain. Moreover, we also find that the ranking results of $S_{\lambda}^{p}$ (Peng \& Dai, 2019) are counterintuitive due to the uncertainty of the $\lambda$ value. If we keep employing accuracy function $S_{\text {liu }}$ of the cases in Table 1, we can conclude that the ultimate results is equal to the introduced score function, which reflects that our introduced score function $S_{p x d}$ is concise and explicit. Hence, the new score function not only can solve the illogical results but also avoid counterintuitive results in simple and clear way. 
Table 1. A comparison with some existing q-ROF score functions

\begin{tabular}{|c|c|c|c|c|c|}
\hline Score function & $q$ & $\begin{array}{c}\text { Case 1 } \\
a=(0.6,0.3) \\
b=(0.5,0.25)\end{array}$ & $\begin{array}{c}\text { Case 2 } \\
a=(0.6,0.3) \\
b=(0.5,0.2)\end{array}$ & $\begin{array}{c}\text { Case 3 } \\
a=(0.4,0.1) \\
b=(\sqrt{0.1501}, 0.01)\end{array}$ & $\begin{array}{c}\text { Case } 4 \\
a=(0.4,0.4) \\
b=(0.5,0.5)\end{array}$ \\
\hline $\begin{array}{c}S_{p x} \\
\text { (Peng et al., 2018) }\end{array}$ & $\begin{array}{l}q=1 \\
q=2 \\
q=3\end{array}$ & $\begin{array}{l}a>b \\
a>b \\
a>b\end{array}$ & $\begin{array}{l}a<b \\
a>b \\
a>b\end{array}$ & $\begin{array}{l}a<b \\
a<b \\
a>b\end{array}$ & $\begin{array}{l}a=b \\
a=b \\
a=b\end{array}$ \\
\hline $\begin{array}{c}S_{l i u} \\
(\text { Liu \& Wang, 2018a) }\end{array}$ & $\begin{array}{l}q=1 \\
q=2 \\
q=3\end{array}$ & $\begin{array}{l}a>b \\
a>b \\
a>b\end{array}$ & $\begin{array}{l}a=b \\
a>b \\
a>b\end{array}$ & $\begin{array}{l}a<b \\
a=b \\
a>b\end{array}$ & $\begin{array}{l}a=b \\
a=b \\
a=b\end{array}$ \\
\hline $\begin{array}{c}S_{\lambda}^{p} \\
\text { (Peng \& Dai, 2019) }\end{array}$ & $\begin{array}{l}q=1 \\
q=2 \\
q=3\end{array}$ & $\begin{array}{l}a=b \\
a>b \\
a>b\end{array}$ & $\begin{array}{l}a>b \\
a>b \\
a>b\end{array}$ & $\begin{array}{l}a<b \\
a<b \\
a>b\end{array}$ & $\begin{array}{l}a>b \\
a>b \\
a>b\end{array}$ \\
\hline$S_{p x d}$ & $\begin{array}{l}q=1 \\
q=2 \\
q=3\end{array}$ & $\begin{array}{l}a>b \\
a>b \\
a>b\end{array}$ & $\begin{array}{l}a>b \\
a>b \\
a>b\end{array}$ & $\begin{array}{l}a<b \\
a<b \\
a>b\end{array}$ & $\begin{array}{l}a<b \\
a<b \\
a<b\end{array}$ \\
\hline
\end{tabular}

\section{Two novel q-rung orthopair fuzzy operations}

For the operations $\ominus$ and $\oslash$ in Definition 3, we can find that the limited conditions are so complicated, which greatly affects its application. Hence, we propose some novel $\ominus$ and $\oslash$ operators to overcome such drawback.

Definition 5. Suppose that $a=\left(\mu_{1}, v_{1}\right)$ and $b=\left(\mu_{2}, v_{2}\right)$ be q-ROFNs, the $\ominus$ and $\oslash$ operations are denoted as
(1) $a \ominus b=\left(\mu_{1} v_{2}, \sqrt[q]{v_{1}^{q}+\mu_{2}^{q}-v_{1}^{q} \mu_{2}^{q}}\right)$;
(2) $a \oslash b=\left(\sqrt[q]{\mu_{1}^{q}+v_{2}^{q}-\mu_{1}^{q} v_{2}^{q}}, v_{1} \mu_{2}\right)$.

Remark 3. Obviously, for any two q-ROFNs $a$ and $b$, the final result of $a \ominus b$ and $a \oslash b$ are still a q-ROFN. Some simple illustrations are shown as follows:

$$
\begin{aligned}
& \text { For }(1),\left(\mu_{1} v_{2}\right)^{q}+\left(\sqrt[q]{v_{1}^{q}+\mu_{2}^{q}-v_{1}^{q} \mu_{2}^{q}}\right) q=\mu_{1}^{q} v_{2}^{q}+v_{1}^{q}+\mu_{2}^{q}-v_{1}^{q} \mu_{2}^{q}= \\
& \mu_{1}^{q} v_{2}^{q}+\mu_{2}^{q}+v_{1}^{q}\left(1-\mu_{2}^{q}\right) \geq 0 \text { and } \\
& \mu_{1}^{q} v_{2}^{q}+\mu_{2}^{q}+v_{1}^{q}\left(1-\mu_{2}^{q}\right) \leq \mu_{1}^{q}\left(1-\mu_{2}^{q}\right)+\mu_{2}^{q}+v_{1}^{q}\left(1-\mu_{2}^{q}\right)= \\
& \left(\mu_{1}^{q}+v_{1}^{q}\right)\left(1-\mu_{2}^{q}\right)+\mu_{2}^{q} \leq 1^{\star}\left(1-\mu_{2}^{q}\right)+\mu_{2}^{q}=1 .
\end{aligned}
$$

Theorem 4. Suppose that $a=\left(\mu_{1}, v_{1}\right)$ and $b=\left(\mu_{2}, v_{2}\right)$ be q-ROFNs, then

(1) $\left(a \bigcup b^{c}\right) \ominus\left(a^{c} \bigcup b\right)=a \ominus b$;

(2) $\left(a \bigcap b^{c}\right) \ominus\left(a^{c} \bigcap b\right)=a \ominus b$;

(3) $\left(a \cup b^{c}\right) \oslash\left(a^{c} \cup b\right)=a \oslash b$;

(4) $\left(a \bigcap b^{c}\right) \oslash\left(a^{c} \bigcap b\right)=a \oslash b$. 
Proof. We just prove the (1), and the (2)-(4) can be similarly obtained.

(1) Let $a=\left(\mu_{1}, v_{1}\right)$ and $b=\left(\mu_{2}, v_{2}\right)$ be two q-ROFNs, then

$$
\begin{aligned}
& \left(a \cup b^{c}\right) \ominus a^{c} \cup b= \\
& \left(\max \left\{\mu_{1}, v_{2}\right\}, \min \left\{v_{1}, \mu_{2}\right\}\right) \ominus\left(\max \left\{v_{1}, \mu_{2}\right\}, \min \left\{\mu_{1}, v_{2}\right\}\right)= \\
& \left(\max \left\{\mu_{1}, v_{2}\right\}^{\star} \min \left\{\mu_{1}, v_{2}\right\}, \sqrt[q]{\min \left\{v_{1}^{q}, \mu_{2}^{q}\right\}+\max \left\{v_{1}^{q}, \mu_{2}^{q}\right\}-\min \left\{v_{1}^{q}, \mu_{2}^{q}\right\} \max \left\{v_{1}^{q}, \mu_{2}^{q}\right\}}\right)= \\
& \left(\mu_{1} v_{2}, \sqrt[q]{v_{1}^{q}+\mu_{2}^{q}-v_{1}^{q} \mu_{2}^{q}}\right)=a \ominus b .
\end{aligned}
$$

Theorem 5 (Associative law). Suppose that $a=\left(\mu_{1}, v_{1}\right), b=\left(\mu_{2}, v_{2}\right)$ and $d=\left(\mu_{3}, v_{3}\right)$ be q-ROFNs, then

(1) $a \ominus b \ominus d=a \ominus(b \oplus d)$;

(2) $a \oslash b \oslash d=a \oslash(b \otimes d)$.

Proof. We just prove the (1), and the (2) can be similarly proved.

(1) Let $a=\left(\mu_{1}, v_{1}\right), b=\left(\mu_{2}, v_{2}\right)$ and $d=\left(\mu_{3}, v_{3}\right)$ be given q-ROFNs, then

$$
\begin{aligned}
& a \ominus b \ominus d= \\
& \left(\mu_{1} v_{2}, \sqrt[q]{v_{1}^{q}+\mu_{2}^{q}-v_{1}^{q} \mu_{2}^{q}}\right) \ominus\left(\mu_{3}, v_{3}\right)= \\
& \left(\mu_{1} v_{2} v_{3}, \sqrt[q]{v_{1}^{q}+\mu_{2}^{q}+\mu_{3}^{q}-v_{1}^{q} \mu_{2}^{q}-v_{1}^{q} \mu_{3}^{q}-\mu_{2}^{q} \mu_{3}^{q}+v_{1}^{q} \mu_{2}^{q} \mu_{3}^{q}}\right) \\
& \text { and } \\
& a \ominus(b \oplus d)= \\
& \left(\mu_{1}, v_{1}\right) \ominus\left(\sqrt[q]{\mu_{2}^{q}+\mu_{3}^{q}-\mu_{2}^{q} \mu_{3}^{q}}, v_{2} v_{3}\right)= \\
& \left(\mu_{1} v_{2} v_{3}, \sqrt[q]{v_{1}^{q}+\mu_{2}^{q}+\mu_{3}^{q}-v_{1}^{q} \mu_{2}^{q}-v_{1}^{q} \mu_{3}^{q}-\mu_{2}^{q} \mu_{3}^{q}+v_{1}^{q} \mu_{2}^{q} \mu_{3}^{q}}\right) .
\end{aligned}
$$

Hence, it can be proved.

Theorem 6 (Commutative law). Suppose that $a=\left(\mu_{1}, v_{1}\right), b=\left(\mu_{2}, v_{2}\right)$ and $d=\left(\mu_{3}, v_{3}\right)$ be q-ROFNs, then

(1) $a \ominus b \ominus d=a \ominus d \ominus b$;

(2) $a \oslash b \oslash d=a \oslash d \oslash b$.

Theorem 7 (Distributive law). Suppose that $a=\left(\mu_{1}, v_{1}\right), b=\left(\mu_{2}, v_{2}\right)$ and $d=\left(\mu_{3}, v_{3}\right)$ be q-ROFNs, then

(1) $(a \bigcup b) \ominus d=(a \ominus d) \cup(b \ominus d)$;

(2) $(a \bigcap b) \ominus d=(a \ominus d) \bigcap(b \ominus d)$;

(3) $(a \bigcup b) \oslash d=(a \oslash d) \cup(b \oslash d)$;

(4) $(a \bigcap b) \oslash d=(a \oslash d) \cap(b \oslash d)$. 
Theorem 8. Suppose that $a=\left(\mu_{1}, v_{1}\right)$ and $b=\left(\mu_{2}, v_{2}\right)$ be q-ROFNs, then

(1) $a \ominus_{\mathrm{O}} b \oplus b=a$;

(2) $a \oslash_{\mathrm{O}} b \otimes b=a$.

Proof. We just prove the (1), and the (2) can be similarly proved.

(1) Let $a=\left(\mu_{1}, v_{1}\right)$ and $b=\left(\mu_{2}, v_{2}\right)$ be two given q-ROFNs, then

$a \ominus_{\mathrm{O}} b \oplus b=$

$\left(\sqrt{\frac{\mu_{1}^{q}-\mu_{2}^{q}}{1-\mu_{2}^{q}}+\mu_{2}^{q}-\frac{\mu_{1}^{q}-\mu_{2}^{q}}{1-\mu_{2}^{q}} \mu_{2}^{q}}, \frac{v_{1}}{v_{2}} v_{2}\right)=$

$\left(\mu_{1}, v_{1}\right)$.

Hence, it can be proved.

Theorem 9. Suppose that $a=\left(\mu_{1}, v_{1}\right)$ and $b=\left(\mu_{2}, v_{2}\right)$ be q-ROFNs, then

(1) $S_{p x d}(a \oplus b) \geq S_{p x d}(a)$;

(2) $S_{p x d}(a \oslash b) \geq S_{p x d}(a)$;

(3) $S_{p x d}(a \ominus b) \leq S_{p x d}(a)$;

(4) $S_{p x d}(a \otimes b) \leq S_{p x d}(a)$;

(5) $S_{\text {liu }}(a \ominus b)-S_{\text {liu }}(b \ominus a)=S_{\text {liu }}(a \oslash b)-S_{\text {liu }}(b \oslash a)=S_{\text {liu }}(a)-S_{\text {liu }}(b)$.

Proof. We just prove the (1) and (5), and the (2)-(4) can be similarly obtained.

(1) Let $a=\left(\mu_{1}, v_{1}\right)$ and $b=\left(\mu_{2}, v_{2}\right)$ be two given q-ROFNs, then

$$
\begin{aligned}
& a \oplus b=\left(\sqrt[q]{\mu_{1}^{q}+\mu_{2}^{q}-\mu_{1}^{q} \mu_{2}^{q}}, v_{1} v_{2}\right) . \\
& \left(\sqrt[q]{\mu_{1}^{q}+\mu_{2}^{q}-\mu_{1}^{q} \mu_{2}^{q}}\right)^{q}-\mu_{1}^{q}=\left(1-\mu_{1}^{q}\right) \mu_{2}^{q} \geq 0, v_{1} v_{2} \leq v_{1},
\end{aligned}
$$

and based on the Theorem 1, we can obtain $S_{p x d}(a \oplus b) \geq S_{p x d}(a)$.

Since $a \ominus b=\left(\mu_{1} v_{2}, \sqrt[q]{v_{1}^{q}+\mu_{2}^{q}-v_{1}^{q} \mu_{2}^{q}}\right)$ and $b \ominus a=\left(\mu_{2} v_{1}, \sqrt[q]{v_{2}^{q}+\mu_{1}^{q}-v_{2}^{q} \mu_{1}^{q}}\right)$,

so we can have

$$
\begin{aligned}
& S_{\text {liu }}(a \ominus b)=\mu_{1}^{q} v_{2}^{q}-\left(v_{1}^{q}+\mu_{2}^{q}-v_{1}^{q} \mu_{2}^{q}\right)=\left(\mu_{1}^{q} v_{2}^{q}+v_{1}^{q} \mu_{2}^{q}\right)-\left(v_{1}^{q}+\mu_{2}^{q}\right) ; \\
& S_{\text {liu }}(b \ominus a)=\mu_{2}^{q} v_{1}^{q}-\left(v_{2}^{q}+\mu_{1}^{q}-v_{2}^{q} \mu_{1}^{q}\right)=\left(\mu_{2}^{q} v_{1}^{q}+v_{2}^{q} \mu_{1}^{q}\right)-\left(v_{2}^{q}+\mu_{1}^{q}\right) .
\end{aligned}
$$

Further,

$$
\begin{aligned}
& S_{\text {liu }}(a \ominus b)-S_{\text {liu }}(b \ominus a)= \\
& \left(\mu_{1}^{q} v_{2}^{q}+v_{1}^{q} \mu_{2}^{q}\right)-\left(v_{1}^{q}+\mu_{2}^{q}\right)-\left[\left(\mu_{2}^{q} v_{1}^{q}+v_{2}^{q} \mu_{1}^{q}\right)-\left(v_{2}^{q}+\mu_{1}^{q}\right)\right]= \\
& \left(\mu_{1}^{q}-v_{1}^{q}\right)-\left(\mu_{2}^{q}-v_{2}^{q}\right)=S_{\text {liu }}(a)-S_{\text {liu }}(b) .
\end{aligned}
$$


Similar, we can have

$S_{\text {liu }}(a \oslash b)-S_{\text {liu }}(b \oslash a)=S_{\text {liu }}(a)-S_{\text {liu }}(b)$.

Consequently,

$S_{\text {liu }}(a \ominus b)-S_{\text {liu }}(b \ominus a)=S_{\text {liu }}(a \oslash b)-S_{\text {liu }}(b \oslash a)=S_{\text {liu }}(a)-S_{\text {liu }}(b)$.

\section{New q-rung orthopair fuzzy decision making method}

\subsection{The introduction of decision making issue}

Suppose that $A=\left\{A_{1}, A_{2}, \cdots, A_{m}\right\}$ be a series of alternatives, $C=\left\{C_{1}, C_{2}, \cdots, C_{n}\right\}$ be a discrete set of criteria, and $W=\left\{w_{1}, w_{2}, \cdots, w_{n}\right\}$ be weight vector with $w_{j} \in[0,1], \sum_{j=1}^{n} w_{j}=1$. Suppose that the assessment of alternative $A_{i}$ with respect to criterion $C_{j}$ be denoted by q-ROF matrix $P=\left(p_{i j}\right)_{m \times n}=\left(\mu_{i j}, v_{i j}\right)_{m \times n}$, which is shown in Table 2 . The framework of developed method is presented in Figure 3.

Table 2. The q-rung orthopair fuzzy MCDM matrix

\begin{tabular}{|c|c|c|c|c|}
\hline & $C_{1}$ & $C_{2}$ & $\ldots$ & $C_{n}$ \\
\hline$A_{1}$ & $\left(\mu_{11}, v_{11}\right)$ & $\left(\mu_{12}, v_{12}\right)$ & $\ldots$ & $\left(\mu_{1 n}, v_{1 n}\right)$ \\
\hline$A_{2}$ & $\left(\mu_{21}, v_{21}\right)$ & $\left(\mu_{22}, v_{22}\right)$ & $\cdots$ & $\left(\mu_{2 n}, v_{2 n}\right)$ \\
\hline$\vdots$ & $\vdots$ & $\vdots$ & $\ddots$ & $\vdots$ \\
\hline$A_{m}$ & $\left(\mu_{m 1}, v_{m 1}\right)$ & $\left(\mu_{m 2}, v_{m 2}\right)$ & $\ldots$ & $\left(\mu_{m n}, v_{m n}\right)$ \\
\hline
\end{tabular}
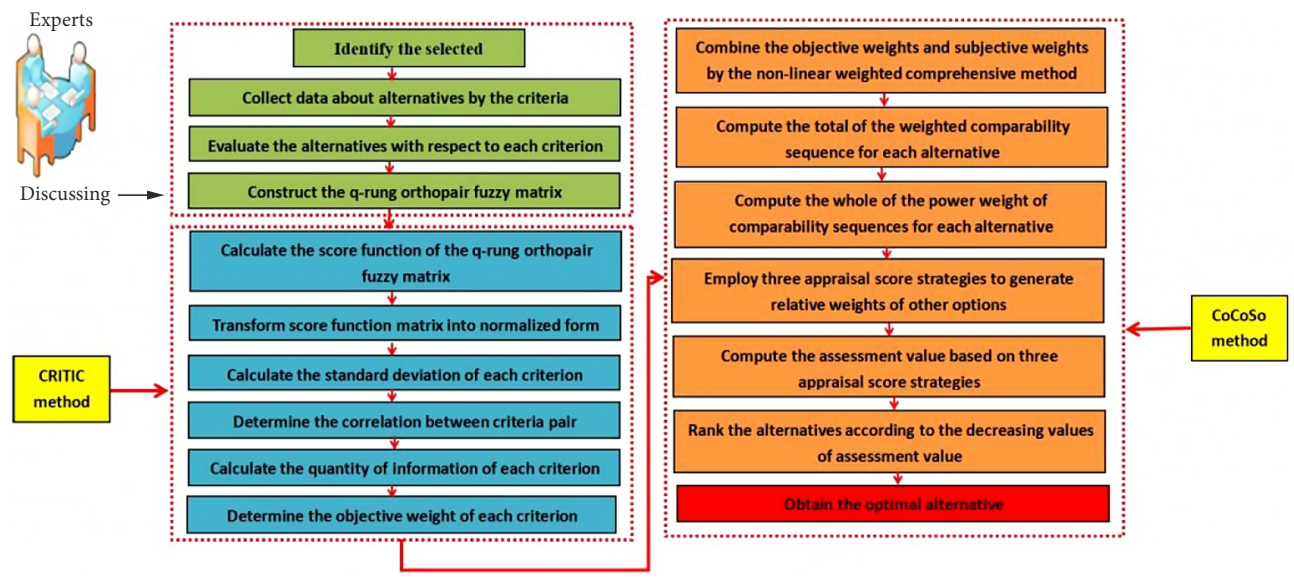

Figure 3. The framework for using the proposed method 


\subsection{Approach to determine combined weights}

\subsubsection{Determine objective weights: CRITIC method}

For the decision making issues, criteria can be regarded as a significant information source (Peng et al., 2019). The vital criteria weights could reveal plentiful information involving in each of them, which is called as "objective weight". The CRITIC (Criteria Importance Through Inter-criteria Correlation) is an approach for computing the objective weights of the given criteria in the MCDM issues (Diakoulaki et al., 1995). The objective weights derived by above approach combine both intensity contrast of each criterion and conflict among criteria. Intensity contrast of criteria is deemed to standard deviation and conflict between them is computed by the correlation coefficient. In current subsection, we branch out this approach into q-ROF environment.

Suppose that $p_{i j}(i=1,2, \cdots, m ; j=1,2, \cdots, n)$ denotes the q-ROF preference value of $i$ th alternative according to $j$ th criterion, $w_{j}^{o}$ represents the fuzzy objective weight of $j$ th criterion, $C$ is a series of cost criteria, and $B$ is a series of benefit criteria. Next, it lists the steps of computing q-ROF objective weights based CRITIC.

Step 1: Compute the score function $R=\left(r_{i j}\right)_{m \times n}(i=1,2, \cdots, m ; j=1,2, \cdots, n)$ of each q-ROFN $p_{i j}=\left(\mu_{i j}, v_{i j}\right)$ by Eq. (7):

$$
r_{i j}=\mu_{i j}^{q}-v_{i j}^{q}-\ln \left(1+\pi_{i j}^{q}\right)
$$

Step 2: Switch the score matrix $R$ into a standard q-ROF matrix $R^{\prime}=\left(r_{i j}^{\prime}\right)_{m \times n}$ by Eq. (8):

where $r_{j}^{-}=\min _{i} r_{i j}$ and $r_{j}^{+}=\max _{i} r_{i j}$.

$$
r_{i j}^{\prime}=\left\{\begin{array}{l}
\frac{r_{i j}-r_{j}^{-}}{r_{j}^{+}-r_{j}^{-}}, \text {if } j \in B, \\
\frac{r_{j}^{+}-r_{i j}}{r_{j}^{+}-r_{j}^{-}}, \text {if } j \in C,
\end{array}\right.
$$

Step 3: Calculate the criteria standard deviations by Eq. (9):

where $\sigma_{j}=\sum_{i=1}^{m} r_{i j}^{\prime} / m$.

$$
\sigma_{j}=\sqrt{\frac{\sum_{i=1}^{m}\left(r_{i j}^{\prime}-\bar{r}_{j}\right)^{2}}{m}},
$$

Step 4: Calculate the correlation between criteria pairs using Eq. (10):

$$
\rho_{j k}=\frac{\sum_{i=1}^{m}\left(r_{i j}^{\prime}-\bar{r}_{j}\right)\left(r_{i k}^{\prime}-\bar{r}_{k}\right)}{\sqrt{\sum_{i=1}^{m}\left(r_{i j}^{\prime}-\bar{r}_{j}\right)^{2} \sum_{i=1}^{m}\left(r_{i k}^{\prime}-\bar{r}_{k}\right)^{2}}} .
$$

Step 5: Calculate the quantity of information of each criterion as follows:

$$
c_{j}=\sigma_{j} \sum_{k=1}^{n}\left(1-\rho_{j k}\right) .
$$

The larger the $c_{j}$ is, the more information a certain criterion contains, so the weight of this evaluation criterion is greater than that of other criteria. 
Step 6: Obtain the objective weight of each criterion as follows:

$$
\varpi_{j}=\frac{c_{j}}{\sum_{j=1}^{n} c_{j}} .
$$

\subsubsection{Determine combined weights: linear weighted integrated method}

Suppose that subjective weight, given by the DMs or experts, is $\omega=\left\{\omega_{1}, \omega_{2}, \cdots, \omega_{n}\right\}$, where $\sum_{j=1}^{n} \omega_{j}=1,0 \leq \omega_{j} \leq 1$. The objective weight, obtained by Eq. (12), is $\varpi=\left\{\varpi_{1}, \varpi_{2}, \cdots, \varpi_{n}\right\}$, where $\sum_{j=1}^{n} \varpi_{j}=1,0 \leq \varpi_{j} \leq 1$.

Hence, combined weight $w=\left\{w_{1}, w_{2}, \cdots, w_{n}\right\}$ can be defined as

where $\sum_{j=1}^{n} w_{j}=1,0 \leq w_{j} \leq 1$

$$
w_{j}=\frac{\varpi_{j} \omega_{j}}{\sum_{j=1}^{n} \varpi_{j} \omega_{j}},
$$

\subsection{The q-rung orthopair fuzzy CoCoSo method}

CoCoSo (Combined Compromise Solution) method is a novel and resultful MCDM method, which is presented by Yazdani et al. (2018). The suggested approach is based on an integrated exponentially weighted product (EWP) and simple additive weighting (SAW) model, which can be a compendium of compromise solutions. In order to solve the MCDM issue, we present a q-ROF-CoCoSo approach.

Generally speaking, the q-ROF-CoCoSo method includes the steps below.

\section{Algorithm 1: CoCoSo}

Step 1: Obtain the q-ROF decision matrix $P=\left(p_{i j}\right)_{m \times n}$.

Step 2: Compute the score function $R=\left(r_{i j}\right)_{m \times n}$ of each q-ROFN $p_{i j}$ by Eq. (7).

Step 3: Switch score the matrix $R=\left(r_{i j}\right)_{m \times n}$ into a standard q-ROF matrix $R^{\prime}=\left(r_{i j}^{\prime}\right)_{m \times n}$ by Eq. (8).

Step 4: Calculate combined weight $w$ by Eq. (13).

Step 5: Compute the total of the weighted comparability sequence for every alternative as $S_{i}:$

$$
S_{i}=\sum_{j=1}^{n} w_{j} r_{i j}^{\prime}
$$

Step 6: Compute the whole of the power weight of comparability sequences for each alternative as $P_{i}$ :

$$
P_{i}=\sum_{j=1}^{n}\left(r_{i j}^{\prime}\right)^{w_{j}}
$$

Step 7: Relative weights of alternatives employing the below aggregation strategies are computed by Eqs (16)-(18): 


$$
\begin{gathered}
k_{i a}=\frac{P_{i}+S_{i}}{\sum_{i=1}^{m} P_{i}+S_{i}} ; \\
k_{i b}=\frac{S_{i}}{\min _{i} S_{i}}+\frac{P_{i}}{\min _{i} P_{i}} ; \\
k_{i c}=\frac{\lambda S_{i}+(1-\lambda) P_{i}}{\lambda \max _{i} S_{i}+(1-\lambda) \max _{i} P_{i}}, 0 \leq \lambda \leq 1 .
\end{gathered}
$$

Step 8: Compute the assessment value $k_{i}$ by Eq. (19).

$$
k_{i}=\sqrt[3]{k_{i a} k_{i b} k_{i c}}+\frac{k_{i a}+k_{i b}+k_{i c}}{3} .
$$

Step 9: Rank alternatives by the decreasing values of assessed value $k_{i}(i=1,2, \ldots, m)$.

Remark 4. It must be explained that the q-ROF-CoCoSo approach whose evaluation value in decision matrix is represented by q-ROFNs. The q-ROFNs are very effective in seizing imprecision of experts or DMs in decision making issues. Moreover, the q-ROF-CoCoSo method is a valuable means to deal with the DM issues with q-ROFNs, which has a grand power in differentiating the given alternatives and achieves the most desired alternative out of counter-intuitive case (Without the process of AOs presented by Peng et al. (2018)). However, other MCDM methods in q-ROF environment fail to possess such precious characteristics.

\subsection{A case study in financial risk evaluation}

In today's society, any enterprise will encounter various financial risks in operation and production. Financial risks are not only difficult to achieve financial benefits, but more likely to threaten the normal operation and production of enterprises. At present, enterprise personnel pay little attention to financial risks, but what I want to say is that financial risks are always around you. Enterprises are one-sided in pursuit of profitable products, ignoring market demand. When the sale also blindly pursues the expansion market, causes the buyer to default on the payment for goods the phenomenon to occur from time to time. Corporate balance sheet has been high, these may be the potential financial risks of enterprises.

When evaluating the financial risk, it is indispensable to design a logical assessment system to guarantee the effective and scientific evaluation results. We construct and depict an evaluation criteria for financial risk as $C_{j}(j=1,2,3,4,5,6,7)$.

The description of each criterion is briefly stated in Table 3.

Example 2. Suppose that there are five enterprises $\mathrm{A}=\left\{A_{1}, A_{2}, A_{3}, A_{4}, A_{5}\right\}$ to be considered for the evaluation of financial risk. The Chief Financial Officer selects the criteria set $C_{j}$ $(j=1,2,3,4,5,6,7)$ as $C_{1}$ (Asset profitability), $C_{2}$ (Debt-paying ability), $C_{3}$ (Economic efficiency), $C_{4}$ (Enterprise development potential), $C_{5}$ (Financial flexibility), $C_{6}$ (Earning power), and $C_{7}$ (Leverage financial risk). According to the characteristics of the financial risk, we can find that $C_{1}, C_{2}, C_{3}, C_{4}, C_{5}, C_{6}$ are benefit criteria and $C_{7}$ is cost criterion. 
Table 3. The evaluation criteria of financial risk

\begin{tabular}{|c|c|}
\hline Criteria & Brief description \\
\hline $\begin{array}{l}\text { Asset profitability } \\
\left(C_{1}\right)\end{array}$ & $\begin{array}{l}\text { It is the ultimate goal of business operation, and it is also the premise } \\
\text { of enterprise survival and development. The profitability is determined by the } \\
\text { total return on assets (representing the profit level of each capital, reflecting } \\
\text { the profit level of the assets used by the enterprise) and the cost and profit } \\
\text { margin (reflecting the higher the profit level of each dollar spent, the stronger } \\
\text { the profitability of the enterprise). }\end{array}$ \\
\hline $\begin{array}{l}\text { Debt-paying ability } \\
\left(C_{2}\right)\end{array}$ & $\begin{array}{l}\text { Indicators for measuring debt-paying ability have current ratios and asset- } \\
\text { liability ratios. If the current ratio is too high, it will cause liquidity to lose } \\
\text { reinvestment opportunities. The average productive enterprise is about } 2 \text {, and } \\
\text { the asset-liability ratio is generally } 40-60 \% \text {. When the return on investment is } \\
\text { bigger than the borrowing rate, the more borrowing, the more profit, and the } \\
\text { greater the financial risk. }\end{array}$ \\
\hline $\begin{array}{l}\text { Economic efficiency } \\
\left(C_{3}\right)\end{array}$ & $\begin{array}{l}\text { High and low directly reflect the level of business management, including: } \\
\text { reflect the asset operating indicators have account receivable turnover rate and } \\
\text { production and sales balance rate (product sales value/industrial output value). }\end{array}$ \\
\hline $\begin{array}{l}\text { Enterprise } \\
\text { development } \\
\text { potential } \\
\left(C_{4}\right)\end{array}$ & $\begin{array}{l}\text { Indicators for measuring the development potential of enterprises include sales } \\
\text { growth rate and capital preservation and appreciation rate. Several values are } \\
\text { specified for each selected evaluation index. The design and calculation of the } \\
\text { individual efficiency coefficients of various indicators are used. The Delphi } \\
\text { method can quantify the financial status of the enterprise. }\end{array}$ \\
\hline $\begin{array}{l}\text { Financial flexibility } \\
\left(C_{5}\right)\end{array}$ & $\begin{array}{l}\text { It refers to the ability of an enterprise to take resultful measures to transform } \\
\text { the flow and time of cash flow for adapting to unexpected opportunities and } \\
\text { needs. It is principally related to the net cash flow generated by the business } \\
\text { activities of enterprises. Indicators reflecting financial elasticity include: } \\
\text { working capital and total assets ratio used to measure the liquidity level of all } \\
\text { assets of an enterprise, principal repayment ratio of matured debts, ratio of } \\
\text { real net asset to tangible long-term asset, accounts receivable and inventory } \\
\text { turnover ratio. }\end{array}$ \\
\hline $\begin{array}{l}\text { Earning power } \\
\left(C_{6}\right)\end{array}$ & $\begin{array}{l}\text { In the long run, a company can stay away from financial crisis, which must } \\
\text { have good profitability, enterprise external financing ability and debt repayment } \\
\text { ability to be stronger. It consists of the following aspects: total assets net cash } \\
\text { ratio, sales net cash ratio and return on equity. }\end{array}$ \\
\hline $\begin{array}{l}\text { Leverage financial } \\
\text { risk } \\
\left(C_{7}\right)\end{array}$ & $\begin{array}{l}\text { Enterprise risk is due to debt, all with their own capital in a business enterprise } \\
\text { management risk without financial risk. Hence, to weigh the leverage of } \\
\text { financial risk to determine the debt ratio, debt should be operating return on } \\
\text { assets and the debt capital cost comparison, only the former is greater than } \\
\text { the latter, due to return of principal and interest can be ensured, and achieve } \\
\text { financial leverage income; At the same time, the debt solvency, that is, the } \\
\text { amount of cash the enterprise has or the liquidity of its assets; The reasonable } \\
\text { allocation of debt capital among various projects. }\end{array}$ \\
\hline
\end{tabular}

Suppose that the DM has the below prior weights $\omega=(0.2,0.1,0.2,0.1,0.14,0.16,0.1)$. The assessments for enterprises arising from the expert in finance department are given in Table 4.

In the following, we employ the developed algorithm $(q=3, \lambda=0.5)$ to choose excellent enterprise. 
Table 4. The q-ROF matrix in Example 2

\begin{tabular}{|c|c|c|c|c|c|c|c|}
\hline & $C_{1}$ & $C_{2}$ & $C_{3}$ & $C_{4}$ & $C_{5}$ & $C_{6}$ & $C_{7}$ \\
\hline$A_{1}$ & $(0.9,0.1)$ & $(0.8,0.1)$ & $(0.8,0.1)$ & $(0.7,0.1)$ & $(0.9,0.1)$ & $(0.8,0.1)$ & $(0.4,0.3)$ \\
\hline$A_{2}$ & $(0.9,0.1)$ & $(0.8,0.1)$ & $(0.8,0.1)$ & $(0.7,0.2)$ & $(0.9,0.1)$ & $(0.8,0.2)$ & $(0.4,0.3)$ \\
\hline$A_{3}$ & $(0.9,0.2)$ & $(0.8,0.2)$ & $(0.8,0.2)$ & $(0.7,0.2)$ & $(0.9,0.1)$ & $(0.8,0.2)$ & $(0.4,0.2)$ \\
\hline$A_{4}$ & $(0.8,0.2)$ & $(0.8,0.2)$ & $(0.8,0.2)$ & $(0.7,0.2)$ & $(0.9,0.2)$ & $(0.8,0.2)$ & $(0.4,0.2)$ \\
\hline$A_{5}$ & $(0.8,0.2)$ & $(0.8,0.2)$ & $(0.8,0.2)$ & $(0.7,0.1)$ & $(0.8,0.2)$ & $(0.8,0.3)$ & $(0.4,0.2)$ \\
\hline
\end{tabular}

Step 1: The q-ROF decision matrix is given in Table 4.

Step 2: Compute the score function $r_{i j}(i=1,2,3,4,5 ; j=1,2,3,4,5,6,7)$ of each q-ROFN $p_{i j}$ by Eq. (7) as:

$$
R=\left(r_{i j}\right)_{5 \times 7}=\left(\begin{array}{lllllll}
0.4890 & 0.1142 & 0.1142 & -0.1624 & 0.4890 & 0.1142 & -0.6096 \\
0.4890 & 0.1142 & 0.1142 & -0.1652 & 0.4890 & 0.1120 & -0.6096 \\
0.4875 & 0.1120 & 0.1120 & -0.1652 & 0.4890 & 0.1120 & -0.6005 \\
0.1120 & 0.1120 & 0.1120 & -0.1652 & 0.4875 & 0.1120 & -0.6005 \\
0.1120 & 0.1120 & 0.1120 & -0.1624 & 0.1120 & 0.1059 & -0.6005
\end{array}\right) .
$$

Step 3: Switch the matrix $R=\left(r_{i j}\right)_{5 \times 7}$ into a standard q-ROF matrix $R^{\prime}=\left(r_{i j}^{\prime}\right)_{5 \times 7}$ by Eq. (8) as:

$$
R=\left(r_{i j}\right)_{5 \times 7}=\left(\begin{array}{ccccccc}
1 & 1 & 1 & 1 & 1 & 1 & 1 \\
1 & 1 & 1 & 0 & 1 & 0.7271 & 1 \\
0.9961 & 0 & 0 & 0 & 1 & 0.7271 & 0 \\
0 & 0 & 0 & 0 & 0.9961 & 0.7271 & 0 \\
0 & 0 & 0 & 1 & 0 & 0 & 0
\end{array}\right)
$$

Step 4: Obtain combined weight $w$ by Eq. (13) as:

$$
\begin{aligned}
& w_{1}=0.1992, w_{2}=0.0762, w_{3}=0.2289, w_{4}=0.1510, w_{5}=0.1159, \\
& w_{6}=0.0762, w_{7}=0.1525 .
\end{aligned}
$$

Step 5: Compute the total of the weighted comparability sequence as $S_{i}$,

$$
S_{1}=7, S_{2}=5.9637, S_{3}=2.9629, S_{4}=1.9631, S_{5}=1 .
$$

Step 6: Compute the whole of the power weight of comparability sequences $P_{i}$ :

$$
P_{1}=1, P_{2}=0.7394, P_{3}=0.4337, P_{4}=0.2347, P_{5}=0.2289 \text {. }
$$

Step 7: Three appraisal score strategies are shown as

$$
\begin{aligned}
& k_{1 a}=0.3716, k_{2 a}=0.3114, k_{3 a}=0.1578, k_{4 a}=0.1021, k_{5 a}=0.0571 ; \\
& k_{1 b}=11.3679, k_{2 b}=9.1934, k_{3 b}=4.8573, k_{4 b}=2.9882, k_{5 b}=2.0000 ; \\
& k_{1 c}=1.0000, k_{2 c}=0.8379, k_{3 c}=0.4246, k_{4 c}=0.2747, k_{5 c}=0.1536 .
\end{aligned}
$$

Step 8: Compute the assessment value $k_{i}$ by Eq. (19) as follows:

$$
k_{1}=5.8631, k_{2}=4.7862, k_{3}=2.5011, k_{4}=1.5593, k_{5}=0.9967 .
$$

Step 9: Rank five enterprises as $A_{1} \succ A_{2} \succ A_{3} \succ A_{4} \succ A_{5}$. 


\subsubsection{The sensitivity analysis of weight information}

In order to make sensitivity analysis of parameter $q$ in weight, we present the radar chart and 2D line chart. According to Figure 4, it can be easily seen that the $q=2$ is a watershed, which the weights $w_{1}, w_{2}, w_{3}, w_{4}$ and $w_{7}$ are firstly increasing and later decreasing with the increase in $q$ while $w_{6}$ keeps in the opposite part. For $w_{5}$ is still decreasing with the increase of $q$. The $w_{4}$ and $w_{2}$ are ranked first place and last place from $q \in[2,9]$, respectively. With respect to the weights $w_{3}, w_{5}$ and $w_{7}$ are less than $w_{1}$ when $q \in[2,9]$.

In order to have a better comparison with the weight information, we give the original weight, objective weight (Wang \& Li, 2018), two existing combined weights (Wang \& $\mathrm{Li}$, 2018; Peng \& Dai, 2019) and the developed combined weight $(q=1,2, \ldots 9)$ in Figure 5. Moreover, for combined weight in (Wang \& Li, 2018), we set the parameter $\mathrm{p}$ in comparing the results with original weight because it has no parameter q. According to Figure 5, we can easily find that the developed combined weight method can efficaciously reveal the objective preference (CRITIC) and subjective preference. However, the objective weight presented by Liu et al. (2018b) fails to reveal the most difference compared with weight offered by experts such as $w_{5}$ and $w_{6}$. For combined weight in (Wang \& Li, 2018), although it can partly reflect the DM's preference $\left(w_{3}\right)$, most of them has no difference. In other words, this combined weight determining model fails to effectively describe the law among the decision values transmitted by expert and subjective weight. For combined weight (Peng \& Dai, 2019), although it can fully reflect the DM's preference with distinct difference, it loses the meaning of weight information $\left(w_{2}, w_{3}, w_{4}\right.$ and $\left.w_{7}\right)$ when $q$ takes other values.

\subsubsection{Influence of the parameters $q$ and $\lambda$ in Algorithm 1}

According to Algorithm 1, it can be easily found that the influence of conclusive ranking related the parameters $q$ and $\lambda$ come from the objective weight method (especially for score function) and CoCoSo method, respectively.

a) $2 \mathrm{D}$ line chart
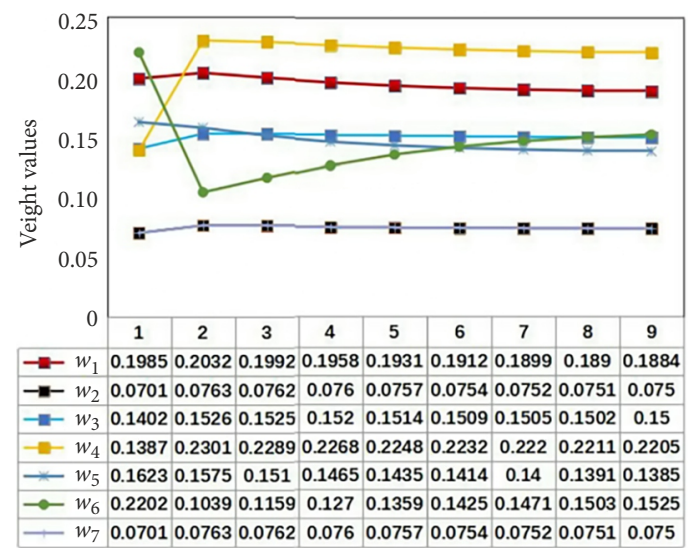

Parameter $q$ b) Radar chart

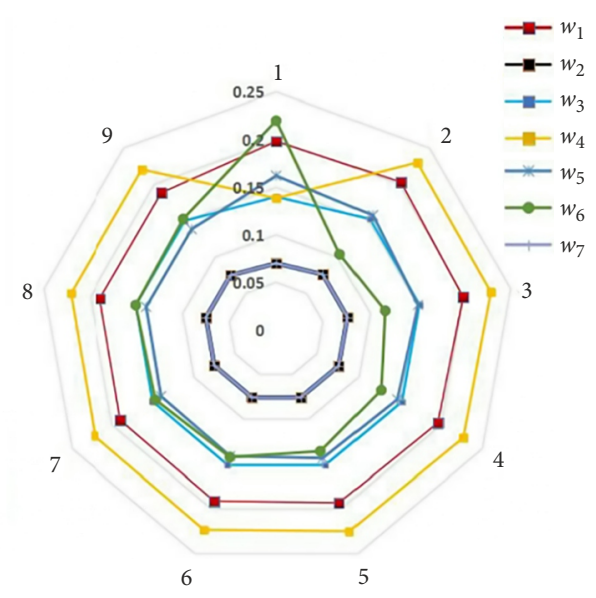

Figure 4. Sensitivity analysis of the combined weight information 
a) The proposed combined weight

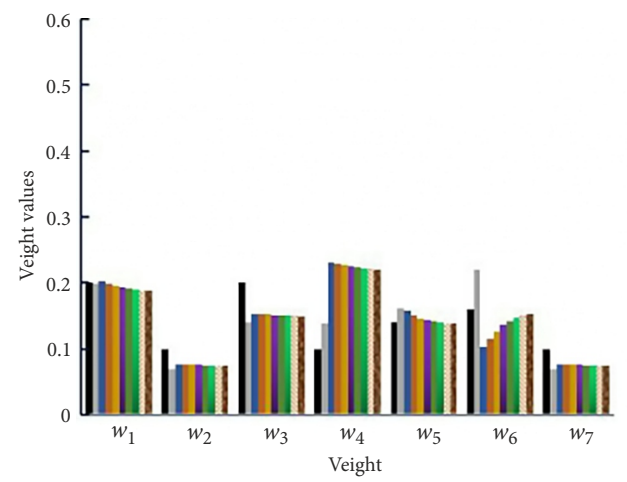

c) The combined weight by Peng and Dai (2019)

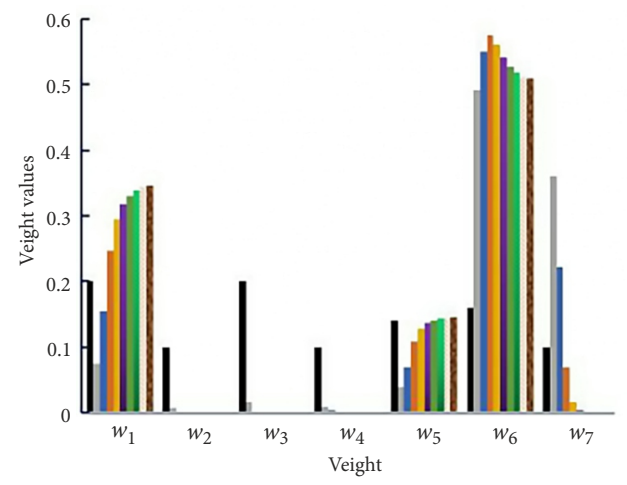

b) The objective weight by Liu et al. (2018b)

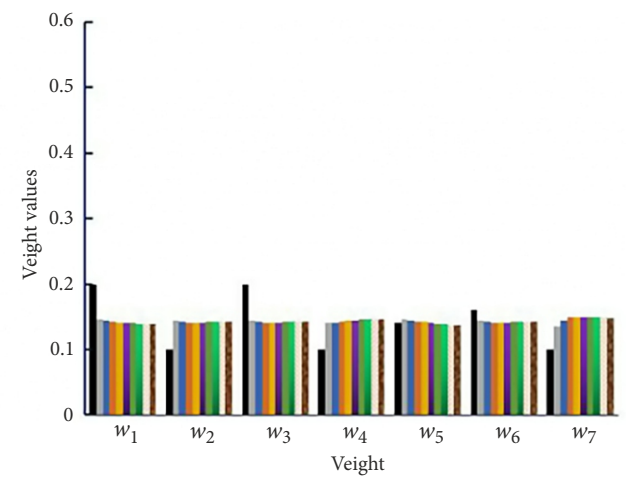

d) The combined weight by Wang and $\operatorname{Li}(2018)$

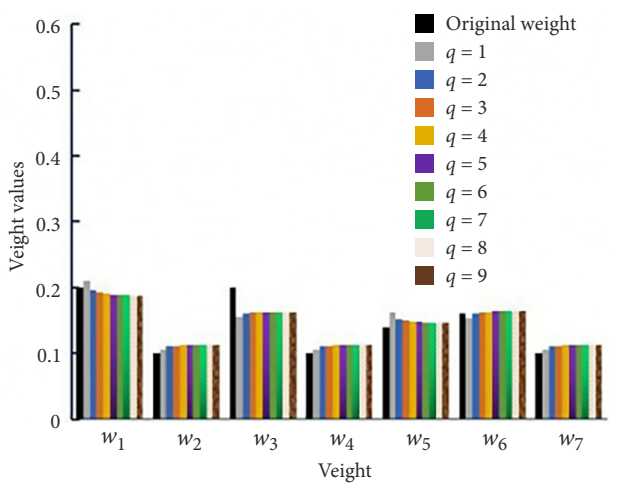

Figure 5. The comparison of the weight information

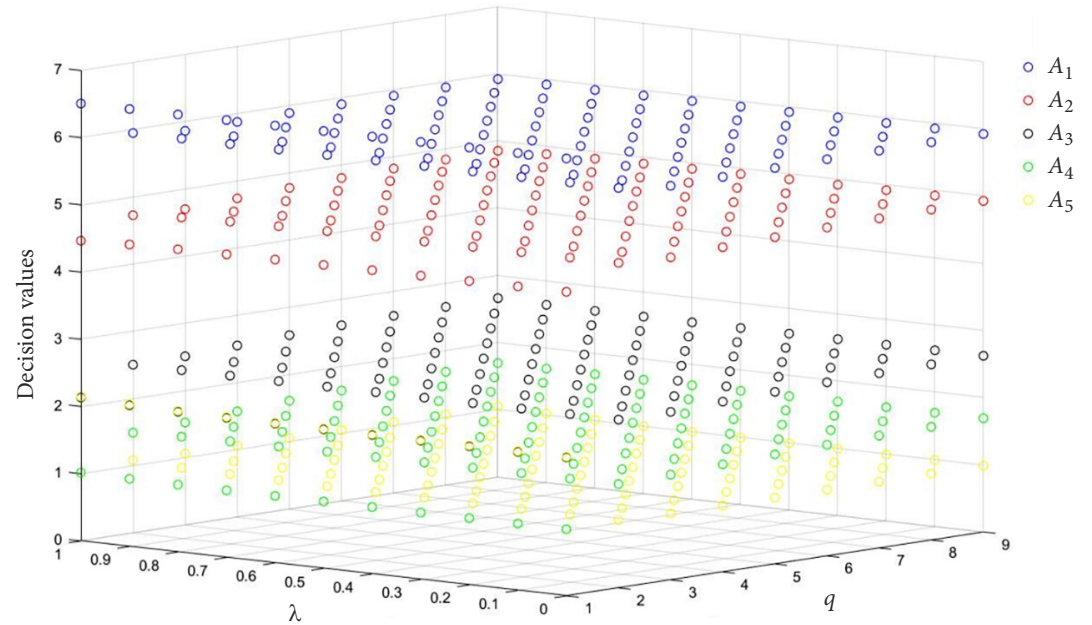

Figure 6. The monolithic changing trend of parameters $q$ and $\lambda$ in Algorithm 1 
According to diverse pairs of parameters, the corresponding assessment values are shown in Figure 6. From these, the almost all of alternatives can be clearly seen in different levels. In other words, it has the better differentiation. Moreover, two key points have been concluded and listed in the following.

1) For a constant value of $\lambda$, it can be found that the decision values with respect to enterprise increase $\left(A_{2}, A_{3}, A_{4}\right)$ or decrease $\left(A_{1}, A_{5}\right)$ along with the increase in parameter $q$ (Figure 7 ). Furthermore, it can be observed that the decision values of entire enterprises are quite change slowly when $q$ increases. Meanwhile, the decision values of enterprise $A_{5}$ is greater than $A_{3}$ and $A_{4}$ from (a) to (k) when $q=1$. Since then, the ranked positions have without any change. However, no matter what it becomes, the decision values of $A_{1}$ and $A_{2}$ are ranked the first place and second place, respectively. From (a) to (k), the most of ranking results all hold as $A_{1} \succ A_{2} \succ A_{3} \succ A_{4} \succ A_{5}$.

a) $\lambda=0$

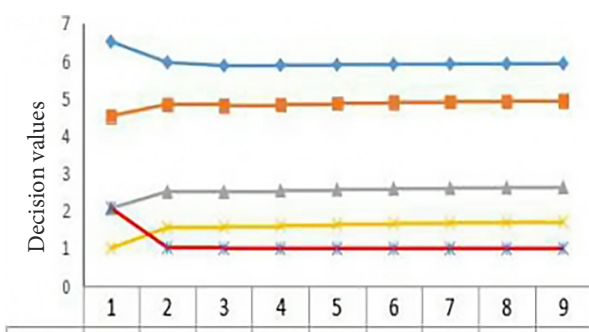

$\rightarrow-A_{1} 6.5071 \quad 5.95 \quad 5.86315 .87665 .89015 .90125 .90965 .91555 .9197$

- $-A_{2} 4.52254 .83434 .79834 .83154 .86114 .88494 .90264 .91524 .924$

$-A_{3} 2.05952 .50332 .49992 .53232 .56032 .58252 .59922 .6112 .6193$

$-A_{4} 0.99261 .54421 .56421 .59971 .62971 .65321 .67061 .68281 .6914$

$\simeq A_{5} 2.06771 .00840 .98690 .98640 .9860 .98570 .98540 .98530 .9852$

The parameter $q$

c) $\lambda=0.2$

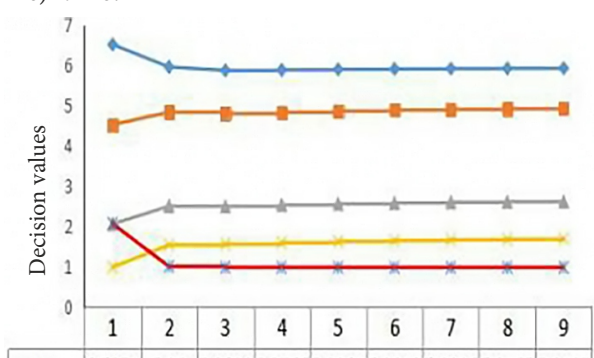

$\rightarrow-A_{1} 6.5071 \quad 5.95 \quad 5.86315 .87665 .89015 .90125 .90965 .91555 .9197$

\begin{tabular}{ll|l|l|l|l|l}
\hline-4 & $A_{2}$ & 4.52074 .8306 & 4.795 & 4.82844 .85834 .8822 & 4.9 & 4.91274 .9216
\end{tabular}

$\rightarrow A_{3} 2.06212 .50332 .50022 .53292 .56112 .58362 .60042 .61232 .6207$

$A_{4} 0.99341 .54241 .56291 .59871 .6291 .65281 .67041 .68281 .6915$

$-A_{5} 2.07041 .01120 .98970 .98910 .98860 .98820 .9880 .98780 .9876$

The parameter $q$

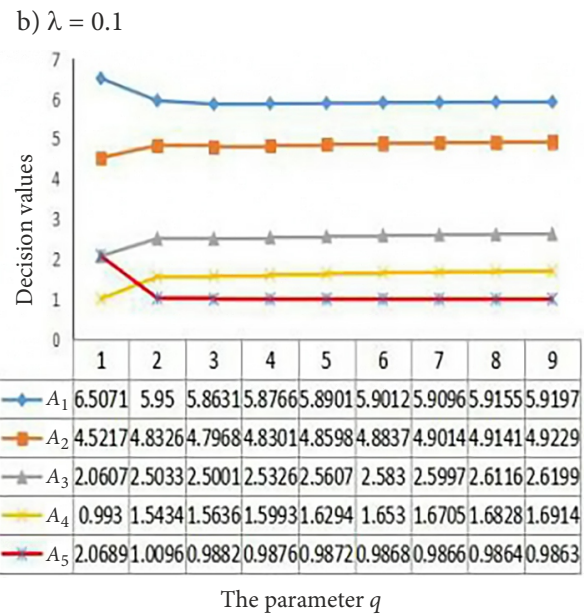

d) $\lambda=0.3$

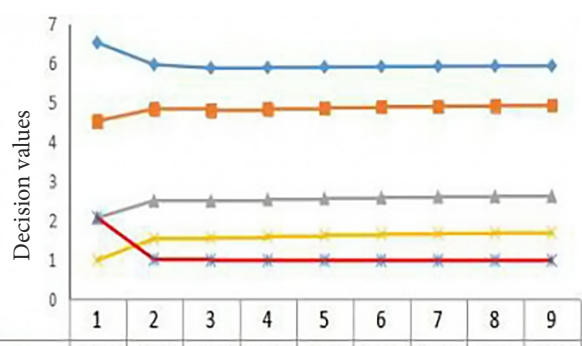

$\neg-A_{1} 6.50715 .955 .86315 .87655 .89015 .90125 .90965 .91555 .9197$

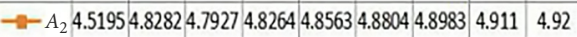

$=A_{3} 2.06392 .50332 .50042 .53342 .56172 .58442 .60132 .61332 .6217$

$-A_{4} 0.99391 .54121 .5621 .59811 .62861 .65261 .67031 .68271 .6915$

$=A_{5} 2.07221 .0130 .99150 .99090 .99030 .98990 .98960 .98940 .9893$

The parameter $q$

Figure 7. To be continue 
e) $\lambda=0.4$

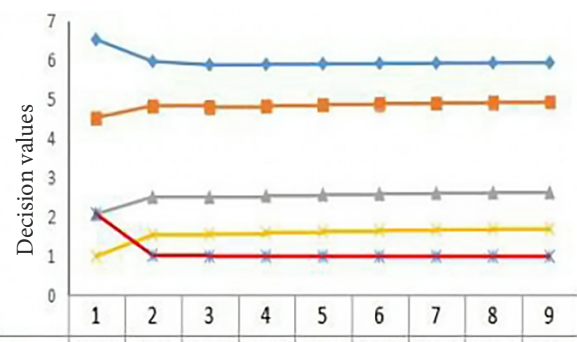

\begin{tabular}{l|l|l|l|l|l}
0 & $A_{1} 6.5071$ & 5.95 & 5.86315 .87665 .89015 .90125 .90965 .91555 .9197
\end{tabular} - $-A_{2} 4.51794 .82514 .78994 .82374 .85394 .87814 .89614 .90894 .9179$ $\longrightarrow A_{3} 2.06612 .50332 .50072 .53392 .56252 .58532 .60232 .61442 .6229$ $A_{4} 0.99461 .53971 .56081 .59731 .62811 .65231 .67011 .68271 .6916$ $-A_{5} 2.07451 .01540 .99380 .99310 .99250 .99210 .99170 .99150 .9913$

The parameter $q$

g) $\lambda=0.6$

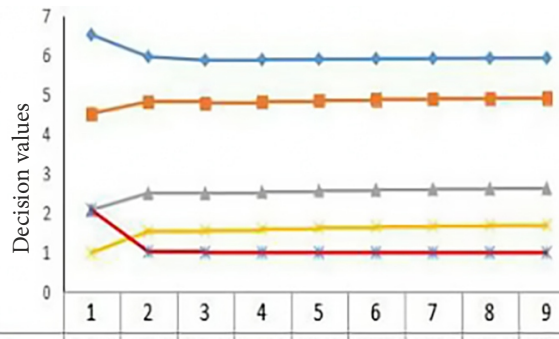

$\because A_{1} 6.50715 .955 .86315 .87665 .89015 .90125 .90965 .91555 .9197$ 든 $A_{2} 4.51314 .81574 .78124 .81564 .8464 \quad 4.8714 .88944 .90244 .9116$ $=A_{3} 2.07292 .50332 .50152 .53552 .56472 .58812 .60562 .61792 .6267$ \begin{tabular}{lllllllllllll}
\hline & $A_{4}$ & 0.9966 & 1.5351 & 1.5573 & 1.5947 & 1.6264 & 1.6513 & 1.6697 & 1.6826 & 1.6917 \\
\hline
\end{tabular} $\longrightarrow A_{5} 2.08141 .02241 .00070 .99980 .99910 .99850 .99810 .99780 .9976$

The parameter $q$

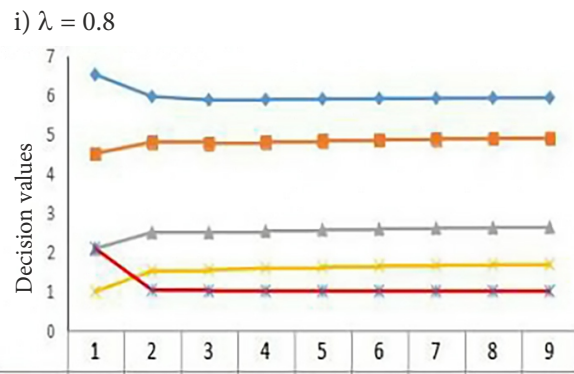

$\rightarrow A_{1} 6.50715 .955 .86315 .87665 .89015 .90125 .90965 .91555 .9197$ -11- $A_{2} 4.50284 .79584 .76284 .79864 .83064 .85624 .87534 .88884 .8984$ \begin{tabular}{ll|l|l|l|l|l|l|l|l|l|l|l|l|l} 
& 2.087 & 2.50322 .5032 & 2.5388 & 2.5695 & 2.594 & 2.6123 & 2.6253 & 2.6344 \\
\hline
\end{tabular}

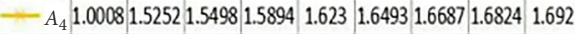
$\because A_{5} 2.09581 .03671 .01471 .01351 .0124 \mid 1.01161 .011 \quad 1.01051 .0102$

The parameter $q$ f) $\lambda=0.5$

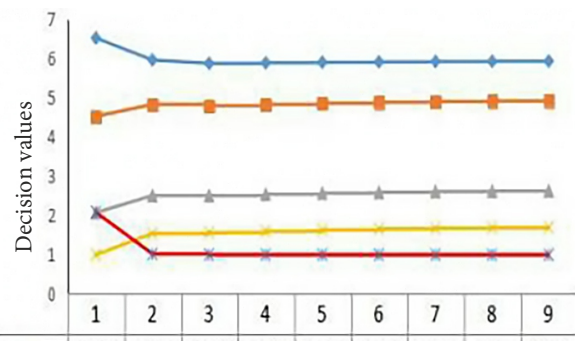

$\rightarrow A_{1} 6.50715 .955 .86315 .87665 .89015 .90125 .90965 .91555 .9197$ -1 $-A_{2} 4.51584 .82114 .78624 .82034 .85074 .87514 .89334 .90624 .9152$ $\rightarrow-A_{3} 2.0692 .50332 .50112 .53462 .56342 .58652 .60372 .61592 .6245$ $-A_{4} 0.99541 .53771 .55931 .59621 .62741 .65191 .66991 .68271 .6916$ $\because A_{5} 2.07741 .01840 .99670 .9960 .99530 .99480 .99440 .99420 .994$

The parameter $q$

h) $\lambda=0.7$

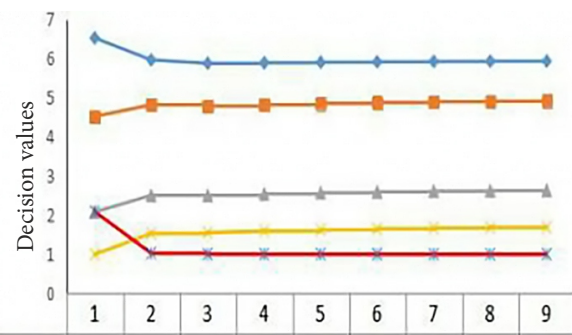

$\rightarrow A_{1} 6.50715 .955 .86315 .87665 .89015 .90125 .90965 .91555 .9197$

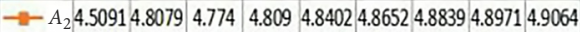
$\rightarrow-A_{3} 2.07842 .50332 .50222 .53682 .56652 .59042 .6082 \quad 2.62082 .6297$

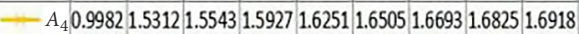
$\nVdash A_{5} 2.08711 .02811 .00621 .00531 .0044 \mid 1.00371 .00321 .00281 .0026$

The parameter $q$

j) $\lambda=0.9$

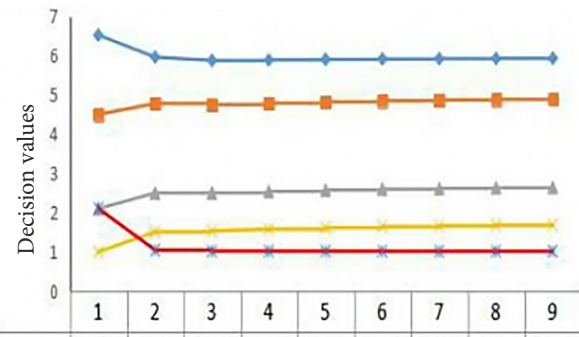

$\rightarrow A_{1} 6.5071 \quad 5.95 \quad 5.86315 .87665 .89015 .90125 .90965 .91555 .9197$ - $-A_{2} 4.49174 .77444 .743 \quad 4.78044 .81364 .84034 .86014 .87434 .8842$ \begin{tabular}{ll|l|l|l|l|l|l|l|l|l|l|l|}
\hline & 2.10182 .5032 & 2.505 & 2.5423 & 2.5745 & 2.6002 & 2.6194 & 2.633 & 2.6426 \\
\hline
\end{tabular} \begin{tabular}{llllllllll}
$-A_{4}$ & 1.0052 & 1.5145 & 1.5417 & 1.5837 & 1.6193 & 1.6471 & 1.6677 & 1.6822 & 1.6923 \\
\hline
\end{tabular} $\because A_{5} 2.1111 .05121 .0291 .02751 .02611 .0251 .02421 .02361 .0232$ The parameter $q$

Figure 7. To be continue 


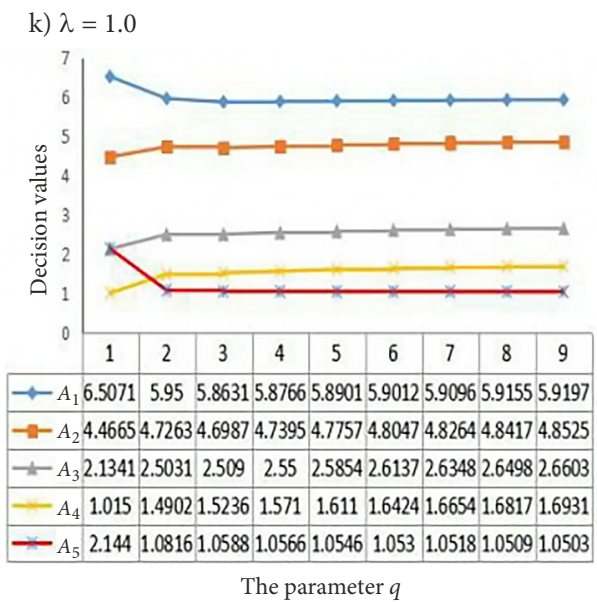

Figure 7. The changing trend of $q$ in diverse $\lambda$

2) For a constant value of $q$, as $\lambda$ increases, the decision values with respect to each enterprise have different variation tendency when $\lambda$ increases. (Figure 8). For alternative $A_{1}$, its decision values still keep the permanent trend without change in values because all preference values in corresponding criteria are biggest, which lead to the final values of Eqs (19) and (20) are their intrinsic values. For alternatives $A_{2}$ and $A_{5}$, their decision values keep as the monotone increasing trend and monotone decreasing trend with gently throughout the whole metabolic process, respectively. For alternative $A_{3}$, most part of them keep as the monotone increasing except for (b). While the most of cases for alternative $A_{4}$ keep as the monotone decreasing except for (a). Moreover, the decision values of $A_{5}$ is bigger than $A_{3}$ and $A_{4}$ in case (a) while $A_{1}$ and $A_{4}$ are bigger than $A_{5}$ in cases (b) to (i). However, no matter what it becomes, the decision values of $A_{1}$ and $A_{2}$ are always the largest and second largest, respectively. From (a) to (i), the most of final ordering results keep as $A_{1} \succ A_{2} \succ A_{3} \succ A_{4} \succ A_{5}$.

a) $q=1$

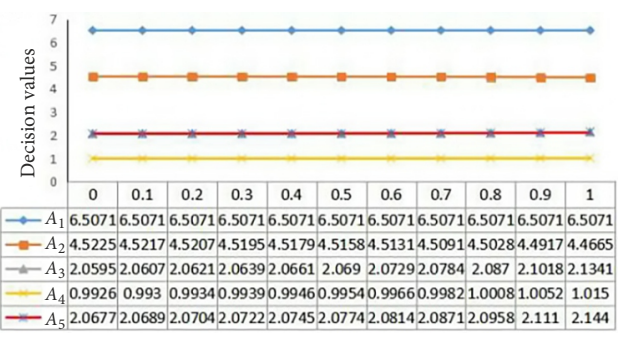

The parameter $q$ b) $q=2$

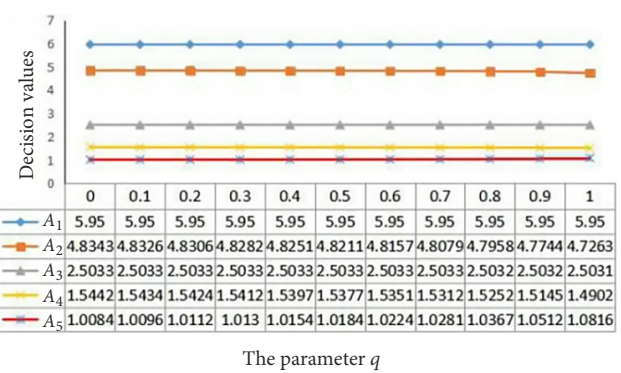

Figure 8. To be continue 
c) $q=3$

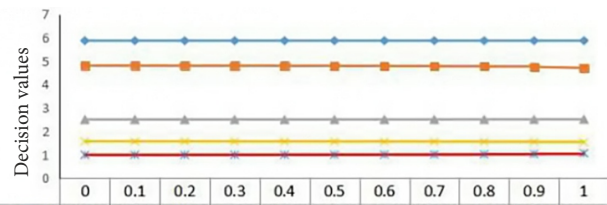
$\rightarrow A_{1} 5.86315 .86315 .86315 .86315 .86315 .86315 .86315 .86315 .86315 .86315 .8631$

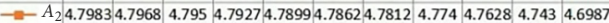


$A_{4} 1.56421 .56361 .56291 .5621 .56081 .55931 .55731 .55431 .54981 .54171 .5236$ $-A_{5} 0.98690 .98820 .98970 .99150 .99380 .99671 .00071 .00621 .01471 .0291 .0588$

The parameter $q$

e) $q=5$

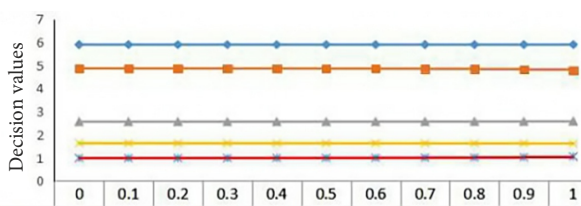

$A_{1} 5.89015 .89015 .89015 .89015 .89015 .89015 .890158901589015 .89015 .8901$ $-A_{2} 4.86114 .85984 .85834 .85634 .85394 .85074 .84644 .84024 .83064 .81364 .7757$ $\rightarrow-A_{3} 2.56032 .56072 .56112 .56172 .56252 .56342 .56472 .56662 .56952 .57452 .5854$

\begin{tabular}{ll|l|l|l|l|l|l|l|l|l|l|l}
$-A_{4}$ & 1.62971 .6294 & 1.629 & 1.62861 .6281 & 1.62741 .62641 .6251 & 1.623 & 1.6193 & 1.611
\end{tabular}

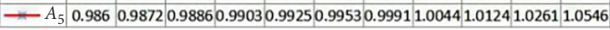

g) $q=7$

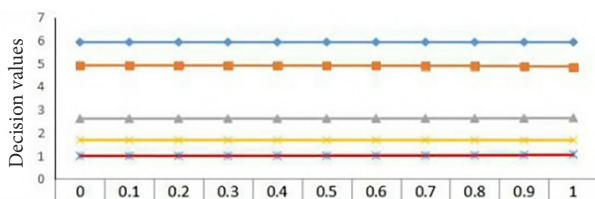

\begin{tabular}{|l|l|l|l|l|l|l|l|l|l|}
0.1 & 0.2 & 0.3 & 0.4 & 0.5 & 0.6 & 0.7 & 0.8 & 0.9 & 1 \\
\hline
\end{tabular} $\rightarrow A_{1}$ 5.90965.9096 5.90965.90965.90965.90965.90965.90965.90965.9096 5.9096 $=-A_{2} 4.90264 .9014 \quad 4.9 \quad 4.89834 .89614 .89334 .88944 .88394 .87534 .86014 .8264$ $4-A_{3} 2.59922 .59972 .60042 .60132 .60232 .60372 .60562 .60822 .61232 .61942 .6348$ $-A_{4} 1.67061 .67051 .67041 .67031 .67011 .66991 .66971 .66931 .66871 .66771 .6654$ $=A_{5} 0.98540 .9866 \quad 0.9880 .98960 .99170 .99440 .99811 .00321 .011 \quad 1.02421 .0518$ The parameter $q$ d) $q=4$

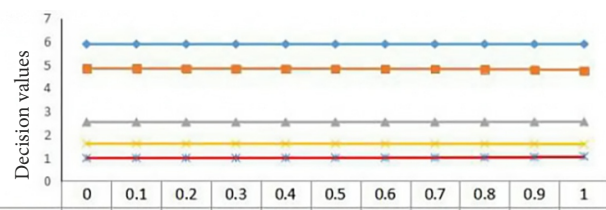
$\rightarrow-A_{1} 5.87665 .87665 .87665 .87665 .87665 .87665 .87665 .87665 .87665 .87665 .8766$ - $-A_{2} 4.83154 .83014 .82844 .82644 .82374 .82034 .81564 .8094 .79864 .78044 .7395$

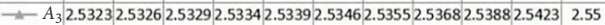
$-A_{4} 1.59971 .59931 .59871 .59811 .59731 .59621 .59471 .59271 .58941 .58371 .571$ $-A_{5} 0.98640 .98760 .98910 .99090 .99310 .9960 .99981 .00531 .01351 .02751 .0566$ The parameter $q$

f) $q=6$

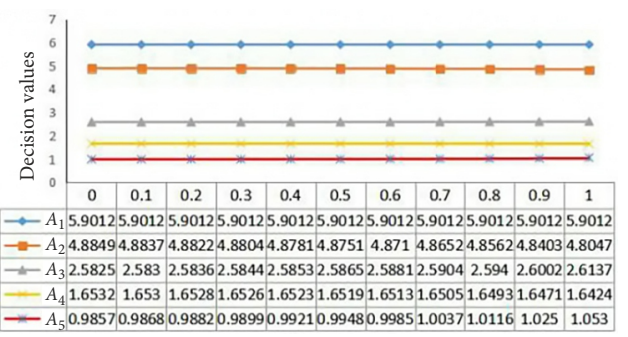
The parameter $q$

h) $q=8$

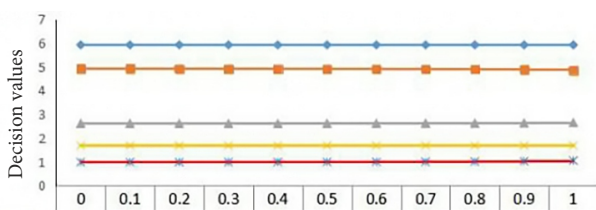
$\rightarrow-A_{1} 5.91555 .91555 .91555 .91555 .91555 .91555 .91555 .91555 .91555 .91555 .9155$ - $-A_{2} 4.91524 .91414 .91274 .9114 .90894 .90624 .90244 .89714 .88884 .87434 .8417$ $\begin{array}{llllllll}-A_{3} & 2.611 & 2.61162 .61232 .6133 & 2.61442 .61592 .61792 .62082 .6253 & 2.633 & 2.6498\end{array}$ $-A_{4} 1.68281 .68281 .68281 .68271 .68271 .68271 .68261 .68251 .68241 .68221 .6817$ $-A_{5} 0.98530 .98640 .98780 .98940 .99150 .99420 .99781 .0028 \mid .01051 .02361 .0509$ The parameter $q$

i) $q=9$

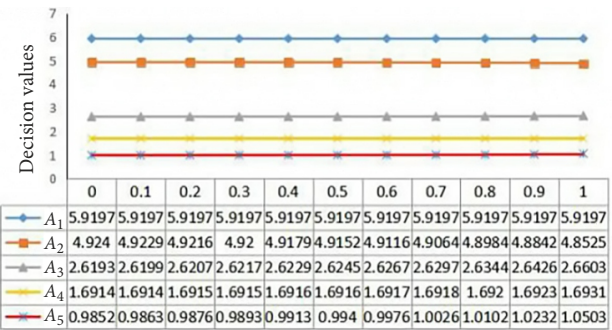

The parameter $q$

Figure 8 . The changing trend of $\lambda$ in diverse $q$ 


\section{A comparison analysis with some existing MCDM methods}

To further verify the availability and preponderance of the explored algorithm, we provide some examples by using some existing MCDM algorithms. In order to unify the comparison scale, we set $q=3$ in q-ROFWA (Liu \& Wang, 2018a) and q-ROFWG (Liu \& Wang, 2018a); $k=7, q=3$ in q-ROFWMSM (Wei et al., 2019) and q-ROFWDMSM (Wei et al., 2019); $p=3$, $t_{k}=3, k=2$ in similarity measure (Peng \& Dai, 2019); $s=t=q=3$ in q-ROFWBM (Liu \& Liu, 2018), q-ROFWGBM (Liu \& Liu, 2018), q-ROFWHM (Liu et al., 2018c), q-ROFGWHM (Wei et al., 2018) and q-ROFWGHM (Wei et al., 2018); $\xi=0.4, \zeta=0.5, \mathrm{n}=2$ in q-ROFPWAD $\xi_{\xi}^{n}$ (Xing et al., 2019), q-ROFPWAF ${ }_{\xi, \zeta}$ (Xing et al., 2019), q-ROFPWAG ${ }_{\xi, \zeta}^{n}$ (Xing et al., 2019), q-ROFPWAH ${ }_{\xi, \zeta}^{n}$ (Xing et al., 2019), q-ROFPWAJ ${ }_{\xi, \zeta}^{n}$ (Xing et al., 2019), q-ROFPWGD ${ }_{\xi}^{n}$ (Xing et al., 2019), q-ROFPWGF ${ }_{\xi, \zeta}^{n}$ (Xing et al., 2019), q-ROFPWGG ${ }_{\xi, \zeta}^{n}$ (Xing et al., 2019), q-ROFPWGH ${ }_{\xi, \zeta}^{n}$ (Xing et al., 2019) and q-ROFPWGJ ${ }_{\xi, \zeta}^{n}$ (Xing et al., 2019).

\subsection{The differentiation degrees of some existing methods}

Some existing methods (Liu \& Wang, 2018a; Xing et al., 2019; Liu \& Liu, 2018) have lower differentiation degrees for final decision making results of all alternatives. In other words, the decision results obtained from them are not resultful and convincing. For a better comparison with some existing algorithms, the related score functions and weight information are adopted by the developed score function and combined weighted. The comparison results are shown in Figure 9 by employing the Example 2. From Figure 9, we can find that the presented MCDM method based CoCoSo has sky-high differentiation degrees.

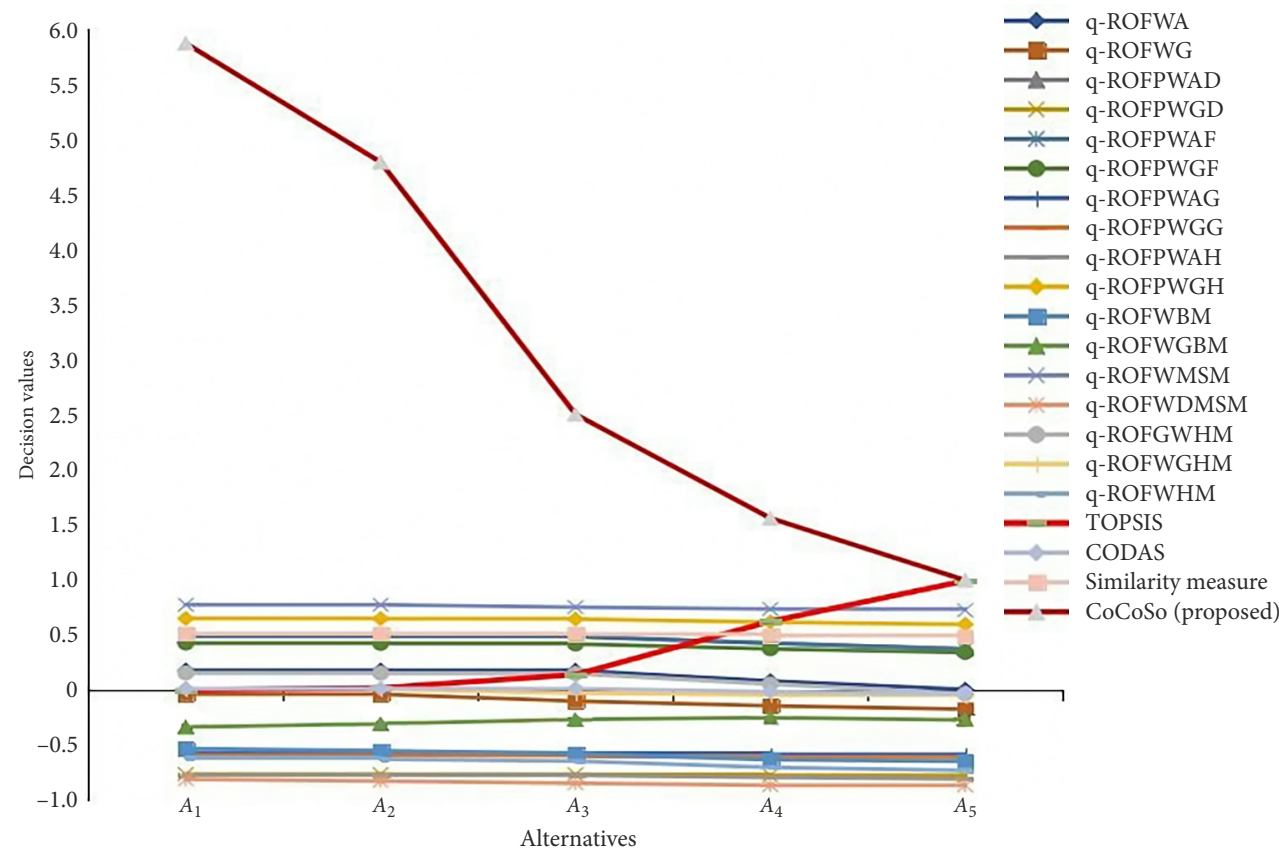

Figure 9. The comparison with existing methods 


\subsection{The counter-intuitive phenomena of some existing methods}

Example 3. Continue to the Example 2. Assume that there has another expert from finance department to give its assessments for enterprises, which is given in Table 5.

Table 5. The q-ROF matrix in Example 3

\begin{tabular}{|c|c|c|c|c|c|c|c|}
\hline & $C_{1}$ & $C_{2}$ & $C_{3}$ & $C_{4}$ & $C_{5}$ & $C_{6}$ & $C_{7}$ \\
\hline$A_{1}$ & $(1,0)$ & $(0.2,0.1)$ & $(0.1,0.1)$ & $(0.2,0.1)$ & $(0.1,0.1)$ & $(0.2,0.1)$ & $(0.2,0.1)$ \\
\hline$A_{2}$ & $(0.9,0.1)$ & $(0.9,0.1)$ & $(0.9,0.1)$ & $(0.9,0.2)$ & $(0.8,0.1)$ & $(0.8,0.1)$ & $(0.1,0.2)$ \\
\hline$A_{3}$ & $(0.9,0.2)$ & $(0.8,0.2)$ & $(0.8,0.2)$ & $(0.7,0.2)$ & $(0.9,0.1)$ & $(0.8,0.2)$ & $(0.2,0.1)$ \\
\hline$A_{4}$ & $(0.9,0.2)$ & $(0.8,0.2)$ & $(0.8,0.2)$ & $(0.7,0.2)$ & $(0.9,0.2)$ & $(0.8,0.2)$ & $(0.2,0.1)$ \\
\hline$A_{5}$ & $(0.9,0.2)$ & $(0.8,0.2)$ & $(0.8,0.2)$ & $(0.7,0.1)$ & $(0.8,0.2)$ & $(0.8,0.3)$ & $(0.2,0.1)$ \\
\hline
\end{tabular}

Table 6. Ranking results and optimal enterprise from diverse methods in Example 3

\begin{tabular}{|c|c|c|}
\hline Methods & Ranking & Optimal enterprise \\
\hline q-ROFWA & $A_{1} \succ A_{2} \succ A_{3} \succ A_{4} \succ A_{5}$ & $A_{1}$ \\
\hline q-ROFWG & $A_{2} \succ A_{3} \succ A_{4} \succ A_{5} \succ A_{1}$ & $A_{2}$ \\
\hline q-ROFPWAD ${ }_{\xi}^{n}$ & $A_{1} \succ A_{2} \succ A_{3} \succ A_{4} \succ A_{5}$ & $A_{1}$ \\
\hline q-ROFPWGD & $A_{2} \succ A_{3} \succ A_{4} \succ A_{5} \succ A_{1}$ & $A_{2}$ \\
\hline q-ROFPWAF ${ }_{\xi, \zeta}^{n}$ & $A_{1} \succ A_{2} \succ A_{3} \succ A_{4} \succ A_{5}$ & $A_{1}$ \\
\hline q-ROFPWGF ${ }_{\xi, \zeta}^{n}$ & $A_{2} \succ A_{3} \succ A_{4} \succ A_{5} \succ A_{1}$ & $A_{2}$ \\
\hline q-ROFPWAG ${ }_{\xi, \zeta}^{n}$ & $A_{2} \succ A_{3} \succ A_{4} \succ A_{5} \succ A_{1}$ & $A_{2}$ \\
\hline q-ROFPWGG ${ }_{\xi, \zeta}^{n}$ & $A_{2} \succ A_{3} \succ A_{4} \succ A_{5} \succ A_{1}$ & $A_{2}$ \\
\hline q-ROFPWAH ${ }_{\xi, \zeta}^{n}$ & $A_{2} \succ A_{3} \succ A_{4} \succ A_{5} \succ A_{1}$ & $A_{2}$ \\
\hline q-ROFPWGH ${ }_{\xi, \zeta}^{n}$ & $A_{2} \succ A_{3} \succ A_{4} \succ A_{5} \succ A_{1}$ & $A_{2}$ \\
\hline q-ROFWBM & $A_{2} \succ A_{3} \succ A_{4} \succ A_{5} \succ A_{1}$ & $A_{2}$ \\
\hline q-ROFWGBM & $A_{2} \succ A_{3} \succ A_{4} \succ A_{5} \succ A_{1}$ & $A_{2}$ \\
\hline q-ROFWMSM & $A_{2} \succ A_{3} \succ A_{4} \succ A_{5} \succ A_{1}$ & $A_{2}$ \\
\hline q-ROFWDMSM & $A_{1} \succ A_{2} \succ A_{3} \succ A_{4} \succ A_{5}$ & $A_{1}$ \\
\hline q-ROFGWHM & $A_{1} \succ A_{2} \succ A_{3} \succ A_{4} \succ A_{5}$ & $A_{1}$ \\
\hline q-ROFWGHM & $A_{2} \succ A_{3} \succ A_{4} \succ A_{5} \succ A_{1}$ & $A_{2}$ \\
\hline q-ROFWHM & $A_{1} \succ A_{2} \succ A_{3} \succ A_{4} \succ A_{5}$ & $A_{1}$ \\
\hline TOPSIS & $A_{2} \succ A_{3} \succ A_{4} \succ A_{5} \succ A_{1}$ & $A_{2}$ \\
\hline CODAS & $A_{2} \succ A_{3} \succ A_{4} \succ A_{5} \succ A_{1}$ & $A_{2}$ \\
\hline Similarity measure & $A_{2} \succ A_{3} \succ A_{4} \succ A_{5} \succ A_{1}$ & $A_{2}$ \\
\hline CoCoSo (proposed) & $A_{2} \succ A_{3} \succ A_{4} \succ A_{5} \succ A_{1}$ & $A_{2}$ \\
\hline
\end{tabular}

Note: The red background color denotes counter-intuitive results. 
Remark 5. From Table 6, we can find that the final ranking and best enterprise by the introduced algorithm are same as the decision results of q-ROFWG (Liu \& Wang, 2018a), q-ROFPWGD ${ }_{\xi}^{n}$ (Xing et al., 2019), q-ROFPWGF ${ }_{\xi, \zeta}^{n}$ (Xing et al., 2019), q-ROFPWAG ${ }_{\xi, \zeta}^{n}$ (Xing et al., 2019), q-ROFPWGG ${ }_{\xi, \zeta}^{n}$ (Xing et al., 2019), q-ROFPWAH ${ }_{\xi, \zeta}^{n}$ (Xing et al., 2019), q-ROFPWGH ${ }_{\xi, \zeta}^{n}$ (Xing et al., 2019), q-ROFWBM (Liu \& Liu, 2018), q-ROFWGBM (Liu \& Liu, 2018) , q-ROFWMSM (Wei et al., 2019), q-ROFWGHM (Wei et al., 2018), TOPSIS (Liu et al., 2019), CODAS (Peng \& Dai, 2019) and Similarity measure (Peng \& Dai, 2019). For q-ROFWA (Liu \& Wang, 2018a), q-ROFPWAD ${ }_{\xi}^{n}$ (Xing et al., 2019), q-ROFPWAF R, $_{\xi}^{n}$ (Xing et al., 2019), q-ROFWDMSM (Wei et al., 2019), q-ROFGWHM (Wei et al., 2018) and q-ROFWHM (Liu et al., 2018c), the final ranking and the best enterprise cannot obtain because of their drawbacks discussed in (Peng \& Dai, 2019). That is to say, the decision results are counter-intuitive and unauthentic.

Example 4. Continue to the Example 2. Assume that there has another expert from finance department to give its assessments for enterprises, which is presented in Table 7.

Table 7. The q-ROF matrix in Example 4

\begin{tabular}{|c|c|c|c|c|c|c|c|}
\hline & $C_{1}$ & $C_{2}$ & $C_{3}$ & $C_{4}$ & $C_{5}$ & $C_{6}$ & $C_{7}$ \\
\hline$A_{1}$ & $(0.9,0.1)$ & $(0.0,1.0)$ & $(0.8,0.1)$ & $(0.8,0.1)$ & $(0.8,0.1)$ & $(0.9,0.1)$ & $(0.2,0.1)$ \\
\hline$A_{2}$ & $(0.3,0.1)$ & $(0.1,0.9)$ & $(0.2,0.1)$ & $(0.3,0.2)$ & $(0.4,0.1)$ & $(0.4,0.1)$ & $(0.1,0.2)$ \\
\hline$A_{3}$ & $(0.3,0.2)$ & $(0.1,0.9)$ & $(0.2,0.2)$ & $(0.3,0.2)$ & $(0.4,0.1)$ & $(0.4,0.2)$ & $(0.2,0.1)$ \\
\hline$A_{4}$ & $(0.3,0.2)$ & $(0.1,0.9)$ & $(0.2,0.2)$ & $(0.3,0.2)$ & $(0.3,0.2)$ & $(0.3,0.2)$ & $(0.2,0.1)$ \\
\hline$A_{5}$ & $(0.3,0.2)$ & $(0.1,0.9)$ & $(0.2,0.2)$ & $(0.3,0.3)$ & $(0.3,0.2)$ & $(0.3,0.3)$ & $(0.2,0.1)$ \\
\hline
\end{tabular}

Table 8. Ranking results and optimal enterprise from diverse methods in Example 4

\begin{tabular}{|l|l|c|}
\hline \multicolumn{1}{|c|}{ Methods } & Ranking & Optimal enterprise \\
\hline q-ROFWA & $A_{1} \succ A_{2} \succ A_{3} \succ A_{4} \succ A_{5}$ & $A_{1}$ \\
\hline q-ROFWG & $A_{2} \succ A_{3} \succ A_{4} \succ A_{5} \succ A_{1}$ & $A_{2}$ \\
\hline q-ROFPWAD R $_{\xi}^{n}$ & $A_{1} \succ A_{2} \succ A_{3} \succ A_{4} \succ A_{5}$ & $A_{1}$ \\
\hline q-ROFPWGD \\
$\xi$ & $A_{2} \succ A_{3} \succ A_{4} \succ A_{5} \succ A_{1}$ & $A_{2}$ \\
\hline q-ROFPWAF $_{\xi, \zeta}^{n}$ & $A_{1} \succ A_{2} \succ A_{3} \succ A_{4} \succ A_{5}$ & $A_{1}$ \\
\hline q-ROFPWGF \\
$\xi, \zeta$ & $A_{2} \succ A_{3} \succ A_{4} \succ A_{5} \succ A_{1}$ & $A_{2}$ \\
\hline q-ROFPWAG $\xi, \zeta$ & $A_{1} \succ A_{2} \succ A_{3} \succ A_{4} \succ A_{5}$ & $A_{1}$ \\
\hline q-ROFPWGG \\
$\xi, \zeta$ & $A_{2} \succ A_{3} \succ A_{4} \succ A_{5} \succ A_{1}$ & $A_{2}$ \\
\hline q-ROFPWAH \\
$\xi, \zeta$ & $A_{1} \succ A_{2} \succ A_{3} \succ A_{4} \succ A_{5}$ & $A_{1}$ \\
\hline q-ROFPWGH \\
$\xi, \zeta$ & $A_{1} \succ A_{2} \succ A_{3} \succ A_{4} \succ A_{5}$ & $A_{1}$ \\
\hline q-ROFWBM & $A_{1} \succ A_{2} \succ A_{3} \succ A_{4} \succ A_{5}$ & $A_{1}$ \\
\hline q-ROFWGBM & $A_{2} \succ A_{3} \succ A_{4} \succ A_{5} \succ A_{1}$ & $A_{2}$ \\
\hline
\end{tabular}


End of Table 8

\begin{tabular}{|l|c|c|}
\hline \multicolumn{1}{|c|}{ Methods } & Ranking & Optimal enterprise \\
\hline q-ROFWMSM & $A_{2} \succ A_{3} \succ A_{4} \succ A_{5} \succ A_{1}$ & $A_{2}$ \\
\hline q-ROFWDMSM & $A_{1} \succ A_{2} \succ A_{3} \succ A_{4} \succ A_{5}$ & $A_{1}$ \\
\hline q-ROFGWHM & $A_{1} \succ A_{2} \succ A_{3} \succ A_{4} \succ A_{5}$ & $A_{1}$ \\
\hline q-ROFWGHM & $A_{2} \succ A_{3} \succ A_{4} \succ A_{5} \succ A_{1}$ & $A_{2}$ \\
\hline q-ROFWHM & $A_{1} \succ A_{2} \succ A_{3} \succ A_{4} \succ A_{5}$ & $A_{1}$ \\
\hline TOPSIS & $A_{1} \succ A_{2} \succ A_{3} \succ A_{4} \succ A_{5}$ & $A_{1}$ \\
\hline CODAS & $A_{1} \succ A_{2} \succ A_{3} \succ A_{4} \succ A_{5}$ & $A_{1}$ \\
\hline Similarity measure & $A_{1} \succ A_{2} \succ A_{3} \succ A_{4} \succ A_{5}$ & $A_{1}$ \\
\hline CoCoSo (proposed) & $A_{1} \succ A_{2} \succ A_{3} \succ A_{4} \succ A_{5}$ & $A_{1}$ \\
\hline
\end{tabular}

Note: The red background color denotes counter-intuitive results.

Remark 6. According to Table 8, we can find that the final ranking and best enterprise by the explored algorithm are same as the methods q-ROFWA (Liu \& Wang, 2018a), q-ROFPWAD $\xi$ (Xing et al., 2019), q-ROFPWAF ${ }_{\xi, \zeta}^{n}$ (Xing et al., 2019), q-ROFPWAG R, $_{\xi, \zeta}$ (Xing et al., 2019), q-ROFPWAH ${ }_{\xi, \zeta}^{n}$ (Xing et al., 2019), q-ROFPWGH R, $_{\xi, \zeta}^{n}$ (Xing et al., 2019), q-ROFWBM (Liu \& Liu, 2018), q-ROFWDMSM (Wei et al., 2019), q-ROFGWHM (Wei et al., 2018), q-ROFWHM (Liu et al., 2018c), TOPSIS (Liu et al., 2019), CODAS (Peng \& Dai, 2019) and Similarity measure (Peng \& Dai, 2019). For q-ROFWA (Liu \& Wang, 2018a), q-ROFPWAD ${ }_{\xi}^{n}$ (Xing et al., 2019), q-ROFPWGF ${ }_{\xi, \zeta}^{n}$ (Xing et al., 2019), q-ROFPWGG ${ }_{\xi, \zeta}^{n}$ (Xing et al., 2019), q-ROFWGBM (Liu \& Liu, 2018), q-ROFWMSM (Wei et al., 2019) and q-ROFWGHM (Wei et al., 2018), the final ranking and the best enterprise fail to obtain because of their drawbacks discussed in (Peng \& Dai, 2019; Huang \& Liang, 2019). That is to say, the decision results are counter-intuitive and suspect.

\section{Conclusions}

The main contributions can be obtained in the following.

1. The novel q-rung orthopair fuzzy score function is proposed, which considers hesitation information that lowering the information distortion. It has great power in differentiating q-ROFNs.

2. The combined weight method is developed based on CRITIC and linear weighted integrated method that to consider both objective and subjective information.

3. The novel operations $(\ominus$ and $\oslash$ ) are given and their relations are proved.

4. The novel q-rung orthopair fuzzy financial risk decision making method based on CoCoSo is explored, which can achieve the best alternative out of counter-intuitive case and has a strong capacity to distinguish the best alternative.

In the future, we will use the remarkable CoCoSo method to handle the financial risk decision making issues under diverse fuzzy environment. 


\section{Conflict of interests}

The authors declare no conflict of interests regarding the publication for the paper.

\section{Acknowledgements}

The authors are very appreciative to the reviewers for their precious comments which enormously ameliorated the quality of this paper.

\section{Funding}

This work was supported by the $<$ National Natural Science Foundation of China \# $1>$ under Grant [number 61462019]; <Funding MOE (Ministry of Education in China) Project of Humanities and Social Sciences \#2> under Grant [number 18YJCZH054]; <Natural Science Foundation of Guangdong Province \#3> under Grant [numbers 2018A030307033,2018A0303130274]; $<$ Social Science Foundation of Guangdong Province \#4> under Grant [number GD18CFX06] and $<$ Special Innovation Projects of Universities in Guangdong Province \#5> under Grant [number KTSCX205].

\section{Author contributions}

Peng Xindong conceived the study and were responsible for the design and development of the data analysis. Huang Haihui were responsible for data collection and analysis.

\section{Disclosure statement}

The authors declare no conflict of interests regarding the publication for the paper.

\section{References}

Atanassov, K. (1986). Intuitionistic fuzzy sets. Fuzzy Sets and Systems, 20(1), 87-96. https://doi.org/10.1016/S0165-0114(86)80034-3

Beliakov, G., Pradera, A., \& Calvo, T. (2007). Aggregation functions: A guide for practitioners ( $1^{\text {th }}$ ed.). Berlin: Springer.

Bonferroni, C. (1950). Sulle medie multiple di potenze. Bollettino Unione Matematica Italiana, 5(3-4), 267-270. http://eudml.org/doc/196058

Chen, S. M., \& Tan, J. M. (1994). Handling multicriteria fuzzy decision-making problems based on vague set theory. Fuzzy Sets and Systems, 67(2), 163-172. https://doi.org/10.1016/0165-0114(94)90084-1

Diakoulaki, D., Mavrotas, G., \& Papayannakis, L. (1995). Determining objective weights in multiple criteria problems: The critic method. Computers \& Operations Research, 22(7), 763-770. https://doi.org/10.1016/0305-0548(94)00059-H

$\mathrm{Du}, \mathrm{W}$. S. (2018). Minkowski-type distance measures for generalized orthopair fuzzy sets. International Journal of Intelligent Systems, 33(4), 802-817. https://doi.org/10.1002/int.21968

$\mathrm{Du}, \mathrm{W}$. S. (2019). Correlation and correlation coefficient of generalized orthopair fuzzy sets. International Journal of Intelligent Systems, 34(4), 564-583. https://doi.org/10.1002/int.22065

Duan, J. (2019). Financial system modeling using Deep Neural Networks (DNNs) for effective risk assessment and prediction. Journal of the Franklin Institute, 356(8), 4716-4731.

https://doi.org/10.1016/j.jfranklin.2019.01.046 
Gao, J., Liang, Z., Shang, J., \& Xu, Z. (2019). Continuities, derivatives and differentials of $q$-rung orthopair fuzzy functions. IEEE Transactions on Fuzzy Systems, 27(8), 1687-1699. https://doi.org/10.1109/TFUZZ.2018.2887187

Gerrard, R., Hiabu, M., Kyriakou, I., \& Nielsen, J. P. (2019). Communication and personal selection of pension saver's financial risk. European Journal of Operational Research, 274(3), 1102-1111. https://doi.org/10.1016/j.ejor.2018.10.038

Goda, K., \& Tesfamariam, S. (2019). Financial risk evaluation of non-ductile reinforced concrete buildings in eastern and western Canada. International Journal of Disaster Risk Reduction, 33, 94-107. https://doi.org/10.1016/j.ijdrr.2018.09.013

Hong, D. H., \& Choi, C. H. (2000). Multicriteria fuzzy decision-making problems based on vague set theory. Fuzzy Sets and Systems, 114(1), 103-113. https://doi.org/10.1016/S0165-0114(98)00271-1

Huang, H. H., \& Liang, Y. (2019). An integrative analysis system of gene expression using self-paced learning and SCAD-Net. Expert Systems with Applications, 135, 102-112. https://doi.org/10.1016/j.eswa.2019.06.016

Liu, D., Chen, X., \& Peng, D. (2019). Some cosine similarity measures and distance measures between q-rung orthopair fuzzy sets. International Journal of Intelligent Systems, 34(7), 1572-1587. https://doi.org/10.1002/int.22108

Liu, P., \& Liu, J. (2018). Some q-rung orthopai fuzzy Bonferroni mean operators and their application to multi-attribute group decision making. International Journal of Intelligent Systems, 33(2), 315-347. https://doi.org/10.1002/int.21933

Liu, P., \& Wang, P. (2018a). Some q-rung orthopair fuzzy aggregation operators and their applications to multiple-attribute decision making. International Journal of Intelligent Systems, 33(2), 259-280. https://doi.org/10.1002/int.21927

Liu, P., \& Wang, P. (2018b). Multiple-attribute decision making based on Archimedean Bonferroni operators of q-rung orthopair fuzzy numbers. IEEE Transactions on Fuzzy Systems, 27(5), 834-848. https://doi.org/10.1109/TFUZZ.2018.2826452

Liu, P., Chen, S. M., \& Wang, P. (2018a). Multiple-attribute group decision-making based on q-rung orthopair fuzzy power Maclaurin symmetric mean operators. IEEE Transactions on Systems, Man, and Cybernetics: Systems, 16 p. https://doi.org/10.1109/TSMC.2018.2852948

Liu, Z., Liu, P., \& Liang, X. (2018b). Multiple attribute decision-making method for dealing with heterogeneous relationship among attributes and unknown attribute weight information under q-rung orthopair fuzzy environment. International Journal of Intelligent Systems, 33(9), 1900-1928. https://doi.org/10.1002/int.22001

Liu, Z., Wang, S., \& Liu, P. (2018c). Multiple attribute group decision making based on q-rung orthopair fuzzy Heronian mean operators. International Journal of Intelligent Systems, 33(12), 2341-2363. https://doi.org/10.1002/int.22032

MacLaurin, C. IV. (1730). A second letter from Mr. Colin McLaurin, Professor of Mathematicks in the University of Edinburgh and F. R. S. to Martin Folkes, Esq; concerning the roots of equations, with the demonstration of other rules in algebra; being the continuation of the letter published in the Philosophical Transactions, $\mathrm{N}^{\circ} 394$. Philosophical Transactions of the Royal Society of London, 36(408), 59-96. https://doi.org/10.1098/rstl.1729.0011

Muirhead, R. F. (1902). Some methods applicable to identities and inequalities of symmetric algebraic functions of $\mathrm{n}$ letters. Proceedings of the Edinburgh Mathematical Society, 21, 144-162. https://doi.org/10.1017/S001309150003460X

Peng, X., \& Dai, J. (2019). Research on the assessment of classroom teaching quality with q-rung orthopair fuzzy information based on multiparametric similarity measure and combinative distancebased assessment. International Journal of Intelligent Systems, 34(7), 1588-1630.

https://doi.org/10.1002/int.22109 
Peng, X., \& Liu, L. (2019). Information measures for q-rung orthopair fuzzy sets. International Journal of Intelligent Systems, 34(8), 1795-1834. https://doi.org/10.1002/int.22115

Peng, X., \& Selvachandran, G. (2019). Pythagorean fuzzy set: state of the art and future directions. Artificial Intelligence Review, 52(3), 1873-1927. https://doi.org/10.1007/s10462-017-9596-9

Peng, X., \& Yang, Y. (2015). Some results for Pythagorean fuzzy sets. International Journal of Intelligent Systems, 30(11), 1133-1160. https://doi.org/10.1002/int.21738

Peng, X., Dai, J., \& Garg, H. (2018). Exponential operation and aggregation operator for q-rung orthopair fuzzy set and their decision-making method with a new score function. International Journal of Intelligent Systems, 33(11), 2255-2282. https://doi.org/10.1002/int.22028

Peng, X., Krishankumar, R., \& Ravichandran, K. S. (2019). Generalized orthopair fuzzy weighted distance- based approximation (WDBA) algorithm in emergency decision-making. International Journal of Intelligent Systems, 34(10), 2364-2402. https://doi.org/10.1002/int.22140

Shu, X., Ai, Z., Xu, Z., \& Ye, J. (2019). Integrations of q-Rung orthopair fuzzy continuous information. IEEE Transactions on Fuzzy Systems, 24(10), 1974-1985. https://doi.org/10.1109/TFUZZ.2019. 2893205

Wang, J., Zhang, R., Li, L., Shang, X., Li, W., \& Xu, Y. (2018, November). Some q-rung orthopair fuzzy dual Maclaurin symmetric mean operators with their application to multiple criteria decision making. In International Symposium on Knowledge and Systems Sciences. Springer, Singapore https://doi.org/10.1007/978-981-13-3149-7_19

Wang, J., Zhang, R., Zhu, X., Zhou, Z., Shang, X., \& Li, W. (2019). Some q-rung orthopair fuzzy Muirhead means with their application to multi-attribute group decision making. Journal of Intelligent \& Fuzzy Systems, 36(2), 1599-1614. https://doi.org/10.3233/JIFS-18607

Wang, R., \& Li, Y. (2018). A novel approach for green supplier selection under a q-rung orthopair fuzzy environment. Symmetry, 10(12), 687. https://doi.org/10.3390/sym10120687

Wei, G., Gao, H., \& Wei, Y. (2018). Some q-rung orthopair fuzzy Heronian mean operators in multiple attribute decision making. International Journal of Intelligent Systems, 33(7), 1426-1458. https://doi.org/10.1002/int.21985

Wei, G., Wei, C., Wang, J., Gao, H., \& Wei, Y. (2019). Some q-rung orthopair fuzzy maclaurin symmetric mean operators and their applications to potential evaluation of emerging technology commercialization. International Journal of Intelligent Systems, 34(1), 50-81. https://doi.org/10.1002/int.22042

Xing, Y., Zhang, R., Zhou, Z., \& Wang, J. (2019). Some q-rung orthopair fuzzy point weighted aggregation operators for multi-attribute decision making. Soft Computing, 23(22), 11627-11649. https://doi.org/10.1007/s00500-018-03712-7

Yager, R. R. (2014). Pythagorean membership grades in multicriteria decision making. IEEE Transactions on Fuzzy Systems, 22(4), 958-965. https://doi.org/10.1109/TFUZZ.2013.2278989

Yager, R. R. (2017). Generalized orthopair fuzzy sets. IEEE Transactions on Fuzzy Systems, 25(5), 12221230. https://doi.org/10.1109/TFUZZ.2016.2604005

Yang, W., \& Pang, Y. (2019). New q-rung orthopair fuzzy partitioned Bonferroni mean operators and their application in multiple attribute decision making. International Journal of Intelligent Systems, 34(3), 439-476. https://doi.org/10.1002/int.22060

Yazdani, M., Zarate, P., Zavadskas, E. K., \& Turskis, Z. (2018). A Combined Compromise Solution (CoCoSo) method for multi-criteria decision-making problems. Management Decision, 57(9), 25012519. https://doi.org/10.1108/MD-05-2017-0458

Ye, J., Ai, Z., \& Xu, Z. (2019). Single variable differential calculus under q-rung orthopair fuzzy environment: Limit, derivative, chain rules, and its application. International Journal of Intelligent Systems, 34(7), 1387-1415. https://doi.org/10.1002/int.22100

Zhang, X., \& Xu, Z. (2014). Extension of TOPSIS to multiple criteria decision making with Pythagorean fuzzy sets. International Journal of Intelligent Systems, 29(12), 1061-1078.

https://doi.org/10.1002/int.21676 